\title{
Review
}

\section{Phytotherapy for treatment of cytokine storm in COVID-19}

\author{
Leena Sapra ${ }^{1}$, Asha Bhardwaj ${ }^{1}$, Zaffar Azam ${ }^{1}$, Deekhsha Madhry ${ }^{1}$, Bhupendra Verma ${ }^{1}$, \\ Sumit Rathore ${ }^{1}$, Rupesh K. Srivastava ${ }^{1, *}$ \\ ${ }^{1}$ Department of Biotechnology, All India Institute of Medical Sciences (AIIMS), 110029 New Delhi, India
}

\section{TABLE OF CONTENTS}

\author{
1. Abstract \\ 2. Introduction \\ 3. Pathogenesis of COVID-19 \\ 4. Immunopathogenesis of COVID-19 \\ 5. Traditional medicine as phytotherapeutics in managing COVID-19 \\ 5.1 Withania somnifera (Ashawagandha) \\ 5.2 Tinospora cordifolia (Guduchi) \\ 5.3 Glycyrrhiza glabra (Yashtimadhu) \\ 5.4 Allium sativum (Garlic) \\ 5.5 Zingiber officinale (Ginger) \\ 5.6 Curcuma longa (Turmeric) \\ 5.7 Cinnamon (Dalchini) \\ 5.8 Moringa oliefera (Drumsticks) \\ 5.9 Azadirachta indica (Neem) \\ 5.10 Ocimum tenuiflorum/sanctum (Tulsi) \\ 5.11 Camellia sinensis (Green tea) \\ 5.12 Astragalus membranaceus (Huangqi) \\ 5.13 Piper longum (Pippali) \\ 5.14 Phyllanthus emblica (Amla) \\ 6. Concluding remarks and future outlook \\ 7. Author contributions \\ 8. Ethics approval and consent to participate \\ 9. Acknowledgment \\ 10. Funding \\ 11. Conflict of interest \\ 12. References
}

\section{Abstract}

In 2020, a novel strain of coronavirus (COVID19) has led to a significant morbidity and mortality worldwide. As of the date of this writing, a total of $116 \mathrm{M}$ cases has been diagnosed worldwide leading to $2.5 \mathrm{M}$ deaths. The number of mortalities is directly correlated with the rise of innate immune cells (especially macrophages) in the lungs that secrete inflammatory cytokines (IL-1 $\beta$ and IL-6) leading to the development of "Cytokine Storm Syndrome" (CSS), multi-organ-failure and death. Given that currently the treatment of this condition is rare and release of effective vaccine might be months away, here, we review the plants and their pharmacologically active-compounds as potential phytopharmaceuticals for the virus induced inflammatory response. Experimental validation of the effectiveness of these natural compounds to prevent or reduce the cytokine storm might be beneficial as an adjunct treatment of SARSCoV-2.

\section{Introduction}

In December 2019, uncommon pneumonia like symptoms began to appear in citizens of Wuhan city, China. A research group at virology institute of China started identifying the agent responsible for the development of these 
atypical symptoms. Next generation sequencing (NGS) data of nucleic acids isolated from the bronchoalveolar lavage fluid (BALF) of diseased patients revealed the presence of a novel coronavirus strain which was provisionally named as 2019-nCoV [1]. The NGS data analysis revealed that the RNA genome of 2019-nCoV resembles the Severe Acute Respiratory Syndrome-Coronavirus (SARS-CoV) genome responsible for the SARS-epidemic during 2003-2004 [2]. Thus, 2019-nCoV was ultimately renamed as SARS-CoV-2. Later, the disease caused by the novel SARS-CoV-2 was designated as COVID-19 by World Health Organization (WHO) which also declared it as an international public health emergency in March 2020 (Fig. 1). The early clinical symptoms associated with SARS-CoV-2 infection are fever, muscle pain, chills, sore throat, loss of taste, dry cough, dyspnea (difficulties in breathing), headache and pneumonia. As of March 2021, 116 million confirmed cases of COVID-19 have been reported worldwide (https://coronavirus.jhu.edu/map.html). The onset of COVID-19 leads to respiratory failure that further causes alveolar damage [3]. This novel strain of coronavirus has become a source of augmenting morbidity and mortality worldwide for the last few months. An extreme inflammatory immune response is believed to be the major cause of disease severity and death in COVID19 patients which involves elevated level of inflammatory cytokines and chemokines (Interleukin (IL)- $1 \beta$, IL-6, tumor necrosis factor (TNF)- $\alpha$, chemokine (CC) ligand-2, CCL-3 and CXCL10), and lymphopenia. Surprisingly, it has been found that the cytokine profile of COVID-19 patients resembles with the patients having cytokine release syndrome. In severe cases, infiltration of mononuclear cells into lungs, spleen, heart and kidney has also been observed [4-6]. The global desolation due to COVID-19 can be partially elucidated by the nature of viral transmission. The incubation period between viral infection and onset of symptoms is around four to seven days that opens a large window for the transmission of SARS-CoV-2 from asymptomatic carriers to healthy individuals [7-9]. Transmission occurs from one person to another mainly through the respiratory droplets released during sneezing or coughing, touching contaminated surfaces or by personal contacts. Most of the patients with severe disease conditions develop acute respiratory distress syndrome (ARDS); a clinical condition that is marked by hypoxemia (reduced ratio of arterial $\mathrm{PO}_{2}$ to inhaled $\mathrm{FiO}_{2}$ ) and bilateral infiltrates [10, 11].

In the case of viral infections, the most commonly adopted therapeutic strategies include the blockage of the viral entry and replication or modulation of humoral and cellular immunity in the uninfected population. Unfortunately, till date, no FDA approved drug is available that can target or limit the entry and replication of SARS-CoV-2. Till date, the pertinent factor involved in disease severity relates to either activation or suppression of immune responses in the host. Several drugs have been repurposed for the treatment of COVID-19 patients like chloroquine, hydroxychloroquine, remdesivir, favipiravir, ritonavir, lopinavir, ribavirin, dexamethasone, arbidol, anti-inflammatory medicines viz. glucocorticoids, tocilizumab and siltuximab (IL-6 cytokine inhibitors) and anakinra (IL-1 cytokine inhibitor) [12]. Currently, convalescent plasma therapy showed effective results against COVID-19 [13]. But these synthetic drugs and therapies exhibit various adverse effects like heart failure, permanent damage to retina as observed in case of hydroxychloroquine and liver damage in case of remdesivir etc. [14]. Thus, there is an exigent need to identify safe and effective therapies with negligible side effects against COVID-19. Several in silico analysis showed that plant derived natural compounds could be effective therapeutic agents against SARS-CoV-2. Plants produce an unbelievable variety of natural compounds with immense therapeutic potential. However, the limited awareness regarding the mechanism of action of natural compounds is a shortcoming that basically prevents the acceptance of plants as phytotherapy by medical professionals. The Ministry of AYUSH, Government of India has recently recommended various immunity promoting measures based on the Ayurveda (the oldest healing science, 5000 years ago) for the prevention and management of COVID-19. Recently, WHO too had endorsed the use of traditional herbs in tackling COVID-19 induced health complications (https://www.afro.who.int/news/expert-panel-endorses-p rotocol-COVID-19-herbal-medicine-clinical-trials). In the present review we have discussed some of the most potent phytotherapeutics available from natural traditional medicines that can be employed by clinicians as therapeutic agents to control viral titer as well as toxicity associated with SARS-CoV-2 infection. Also, we offer suggestions to understand the significance of natural herbs and their utilization to enhance anti-viral immunity in the host.

\section{Pathogenesis of COVID-19}

Coronavirus belongs to a large family of enveloped, non-segmented, positive $(+)$ sense single stranded RNA viruses that circulate in animals including bats, cats, dogs, camels etc. These viruses are named as coronaviruses due to the resemblance of their structure to a crown or corona. Coronavirus are known to cause disease in both animals and humans. Among all coronaviruses, four human coronavirus strains (OC43, NL63, HKU1 and 229E) are known to infect upper respiratory tract with minor symptoms [15]. On the other hand, three human coronavirus strains (SARS-CoV, SARS-CoV-2 and MERS) are known to infect lower respiratory tract that can develop pneumonia and lead to deadly condition. SARS-CoV-2 is a beta coronavirus that shares $79 \%$ genetic sequence similarity with SARS-CoV and 98\% homology with RaTG13 coronaviruses residing in chrysanthemum bats [1]. Moreover, 


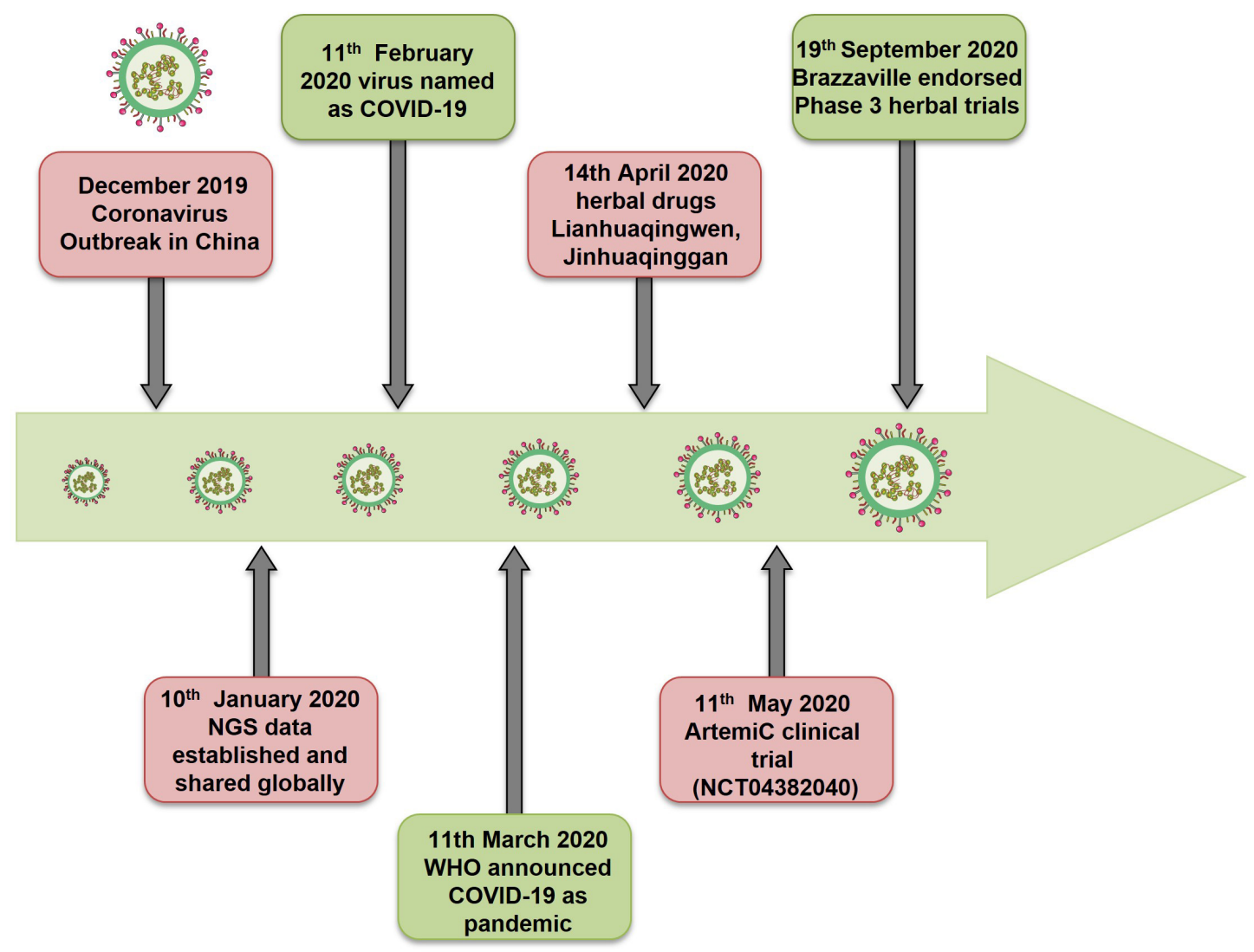

Fig. 1. Timeline of COVID-19. Revisiting the events of Coronavirus pandemic and therapeutics.

immunopathogenesis of SARS-CoV-2 that leads to airways destruction closely resembles with SARS-CoV [16]. In severe cases of infection with SARS-CoV-2, ARDS condition develops that causes respiratory failure which is found to be the major cause of mortality [17]. In addition to this, mounting of immune responses against viral infection causes release of enhanced levels of inflammatory cytokines from the innate immune cells thereby leading to the development of “Cytokine Storm Syndrome” (CSS) [17]. This condition results in uncontrollable inflammation that further impose multiple-organ failure eventually leading to death. Thus, we can infer from these findings that viral infections are not solely responsible for airways destruction, but the host immune response also plays a vital role in the advancement of disease. Furthermore, severity of the disease is found to be correlated with advanced ageing and with the presence of comorbidities [18].

The first step involved in the pathogenesis of COVID-19 is the binding of virus to the host cells (such as airway epithelial cells, endothelial cells, alveolar macrophages, and alveolar epithelial cells) in the lungs. All these cells express Angiotensin Converting Enzyme 2 (ACE2); the target receptor that makes these cells susceptible to coronavirus infection [5]. After infection, a reduction in the pulmonary ACE2 expression is observed and loss of ACE2 might be responsible for enhanced severity of the disease. Generally, ACE2 is known to regulate the Renin-Angiotensin-System (RAS) which in turn regulates the blood pressure and electrolytes/fluid levels and dysfunction of RAS system has been observed in patients infected with SARS-CoV-2. The corona virion comprises of four proteins (viz. spike-S, envelop-E, membrane-M and nucleocapsid-N) and a single stranded RNA genome having a length of 29,900 nucleotides (Fig. 2). Spike (S) protein of SARS-CoV-2 aids the interaction of the virus with target cells expressing ACE2 on their surface. In addition to ACE2, serine protease TMPRSS2 known to be the priming factor for $\mathrm{S}$ protein that facilitates the entry of SARSCoV-2 into the host cell [19]. However, the reason behind the broad dissemination of SARS-CoV-2 is not reported till date. Recently, it is observed that host protease furin which results in cleavage of full-length $\mathrm{S}$ glycoprotein into polybasic S1 and S2 polypeptides resulting in exposure of Arg-Arg-Ala-Arg C-terminal sequence (CendR motif) in S1 polypeptide that aids in binding of virus to host cells via Neuropilin-1 (NRP1) receptor. NRP-1 is expressed on various human tissues such as respiratory tract, neurons and blood vessels. Thus, we can conclude that NRP serves as a second key host receptor that involves in SARS-CoV-2 infection and may provide a therapeutic target for COVID-19 [20]. 


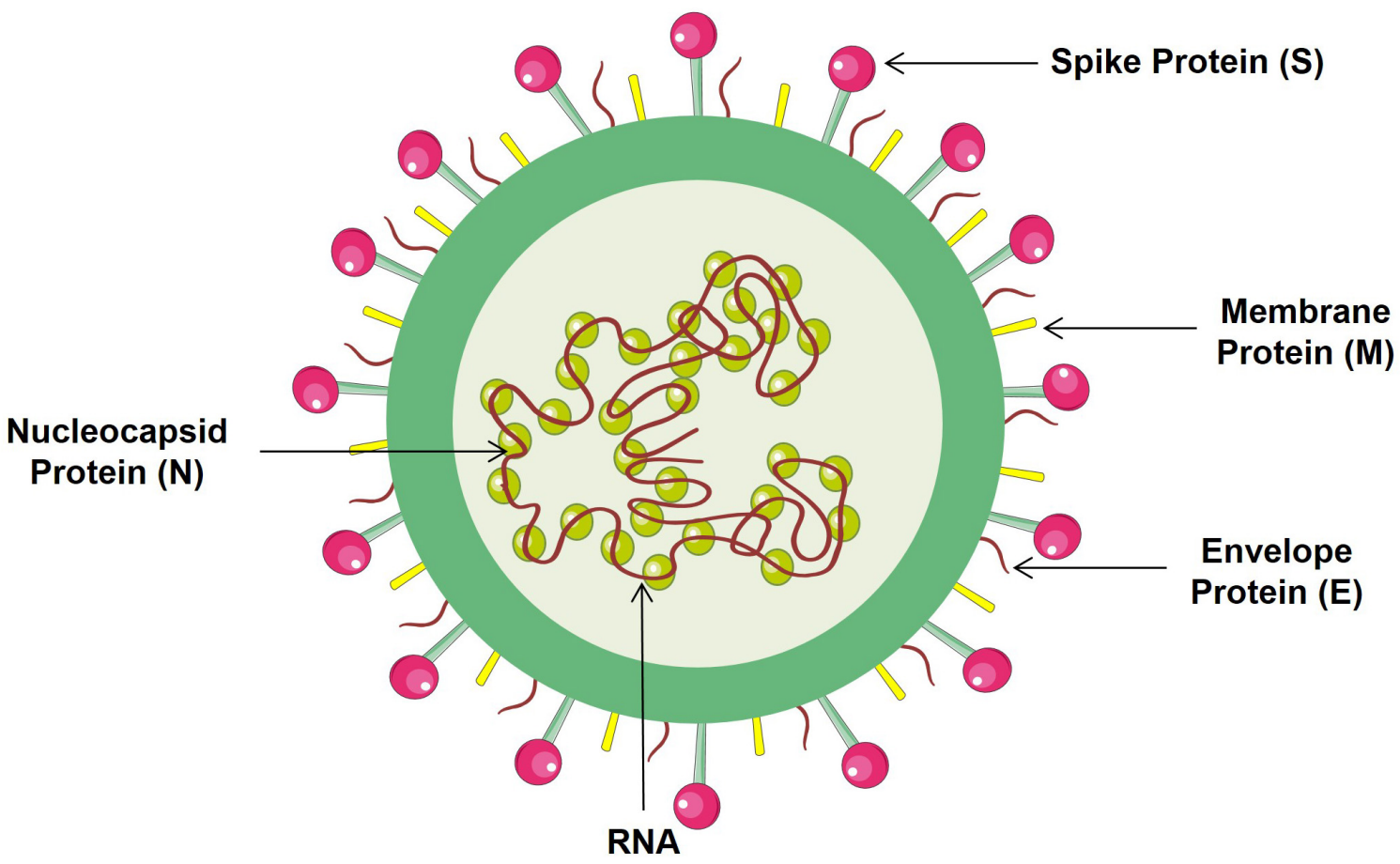

\begin{tabular}{|c|l|}
\hline Structural Proteins & \multicolumn{1}{|c|}{ Functions of Proteins } \\
\hline Spike Protein (S) & $\begin{array}{l}\text { Facilitates the interaction between COVID-19 and host } \\
\text { cells expressing ACE2 }\end{array}$ \\
\hline Membrane Protein (M) & $\begin{array}{l}\text { Abundant protein that defines the shape of viral envelope } \\
\text { and plays a vital role in formation of virus particles }\end{array}$ \\
\hline Envelope Protein (E) & Interacts with M proteins to form the envelope of virus \\
\hline Nucleoprotein (N) & $\begin{array}{l}\text { Interacts with viral RNA genome and assist in RNA } \\
\text { synthesis and folding }\end{array}$ \\
\hline
\end{tabular}

Fig. 2. Structure of COVID-19. COVID-19 structure is comprised of four proteins and single stranded RNA genome. (Figure illustrated with the help of https://smart.servier.com/).

Surprisingly, it has also been observed that males are highly susceptible to SARS-CoV-2 infection as compared to females [21]. Further, the sex-hormones like estrogen and testosterone exhibit different immunomodulatory properties [22-24]. Thus, highlighting the significance of sex steroid hormones for their possible role in disease severity among males in comparison to females. In case of SARS-CoV, a study reported that treatment with estrogen receptor antagonist or estrogen deficiency in ovariectomized female mice dramatically enhanced the morbidity and mortality in female mice due to virus infection $[21,25]$. Recently, a study highlighted the association between Kawasaki disease (KD) and COVID-19 in infants [26]. Furthermore, a study revealed that the developing human embryo also expresses ACE2 receptor and TMPRSS2 protease necessary for virus internalization [27]. Thus, these findings abolish the misconception that only the aged population is highly susceptible to SARS-CoV-2 infection.

\section{Immunopathogenesis of COVID-19}

Viral infections induce the host innate and adaptive immune responses. These responses are initiated with the activation of the innate immune system that recognizes various molecular patterns such as pathogen associated molecular patterns (PAMPs) and death associated molecular patterns (DAMPs) like ATP, nucleic acids and ASC oligomers. Adaptive immune system is activated with the induction of $\mathrm{T}$ cells and the release of various antigen specific antibodies by the $\mathrm{B}$ cells. Activation of innate and adaptive immune response stimulates the release 
of various proinflammatory cytokines and chemokines that further promote the recruitment of macrophages and neutrophils at the site of infection. These cells secrete various cytotoxic substances which are required to clear the infection. These well-coordinated adaptive and innate immune responses generally eliminate the viral infection but sometimes viral infection results in activation of intense inflammatory response resulting in excessive destruction of host tissue. This disproportionate immune response has been hypothesized to be the reason of immunopathogenesis observed in COVID-19. SARS-CoV-2 infection induced extreme inflammation causing the production of large amount of pro-inflammatory cytokines and chemokines. Remarkably, it has been observed that COVID-19 patients who were admitted to intensive care unit (ICU) had higher levels of inflammatory cytokines such as IL-2, IL-7, IL-10, IFN- $\gamma$ induced protein (IP)-10, TNF, Granulocyte-colony stimulating factor (G-CSF), macrophage inhibitory protein 1-alpha (MIP1- $\alpha$ ), macrophage chemoattractant protein1(MCP-1) as compared to the plasma of patients not admitted in the ICU [28]. Other studies also showed that COVID-19 patients have higher levels of IL-6 as compared to healthy individuals [29]. In consistent to this in a clinical study, it has been observed that COVID-19 patients harbor extended population of IL- $1 \beta$ and IL-6 secreting $\mathrm{CD} 4^{+} \mathrm{CD}_{16}{ }^{+}$monocytes in circulation as compared to healthy controls $[14,18]$. The elevation in levels of these cytokines leads to the generation of "cytokine storm" which is primarily responsible for ARDS and multi-organ failure observed in COVID-19 patients. These inflammatory cytokines also further upregulate the inflammatory cascade in resident macrophages that in turn leads to the release of pronounced levels of IL- $1 \beta$ and IL-6 inflammatory cytokines causing the recruitment of neutrophils and $\mathrm{CD}^{+}$ $\mathrm{T}$ cells to the site of infection [29]. These cells produce cytotoxic substances like reactive oxygen species (ROS), matrix-metalloproteinase (MMPs), leukotriene that causes tissue injury in lung parenchyma of host resulting in diseases like acute lung injury (ALI) and ARDS. Surprisingly, a study demonstrated that level of IL-6 is also interrelated with SARS-CoV-2 RNA (RNAemia) [30] and higher level of IL-6 is further interrelated with the need for mechanical ventilation. Thus, IL-6 can be utilized as a biomarker for the assessment of disease severity in infected patients. Therefore, it is worth asking whether SARS-CoV-2 is solely responsible for damaging multiple tissues or it is the cytokine storm or the synergistic effect of both that causes multiorgan damage in the COVID-19 patients. Also, whether blocking the pro-inflammatory mediators would affect the clinical outcome of patients infected with SARS-CoV-2 is still a matter of debate.

Moreover, insufficient activation of the anti-viral cytokines viz. type I and type III interferon is found to be the crucial factor contributing to the failure of innate immune response thereby enhancing viral dissemination and persistence. Thus, the identification of molecular mechanisms responsible for reduced expression of anti-viral cytokines would be crucial for the development of directed immunomodulatory strategies for COVID-19 treatment.

Along with the cytokine storm, lymphopenia is one of the critical clinical manifestations observed in COVID-19 patients [31]. Lymphopenia is defined as the condition in which a substantial reduction in the lymphocyte counts mainly $\mathrm{CD}^{+}{ }^{+}$and $\mathrm{CD} 8^{+} \mathrm{T}$ cells is observed in peripheral blood. A study reported in 2004, demonstrated that lymphocytes lack ACE2 expression [32]. Thus, it is reasonable to postulate the existence of an alternative mechanism through which SARS-CoV-2 compromises the $\mathrm{T}$ cell population. It is still an open question in the research community. Recently, terminal deoxynucleotidyl transferase dUTP nick end labeling (TUNEL) staining suggested apoptosis of lymphocytes in the secondary lymphoid organs (spleen and lymph nodes) of patients who died from COVID-19. These patients showed higher expression of FAS (death receptor) suggesting towards activation induced cell death (AICD) [33]. Apart from AICD, a study reported that $\mathrm{T}$ cells isolated from the circulation and lung tissue of infected patients displayed higher expression of T cells exhaustion markers such as T-cell immunoglobulin and mucin domain-3 (Tim-3) and programmed cells death receptor-1 (PD-1) [6].

Notably, a study reported that the degree of lymphopenia (lymphocyte count $\left.<1.0 \mathrm{pm} 10^{9} / \mathrm{L}\right)^{3}$ and cytokine storm were higher in severe cases of COVID-19 as compared to mild cases. Thus, we can infer from this that inflammatory cytokine levels have an inverse correlation with the $\mathrm{T}$ cell population. Accordingly, these parameters are indicative of disease severity. The analysis of lymphocyte level and cytokine profile in PBMCs of 40 COVID-19 positive patients revealed that the count of lymphocytes especially $\mathrm{CD}^{+} \mathrm{T}$ cells was lower whereas, the neutrophil count was higher in severe cases as compared to mild cases [34]. Therefore, N8R (Neutrophil to $\mathrm{CD}^{+}{ }^{+} \mathrm{T}$ cells ratio) and NLR (Neutrophil to lymphocytes ratio) may also serve as a prognostic biomarker for the identification of severe COVID-19 cases.

\section{Traditional medicine as phytotherapeutics in managing COVID-19}

Traditional medicines have long antiquity in playing a central role in the prevention as well as in the management of several diseased conditions. They have a holistic concept that works by strengthening the body resistance to eradicate pathogenic factors. Recently, the significance of traditional medicines has also been proven in the management of COVID-19 pandemic. A study reported that early involvement of traditional medicine improves the recovery rate and reduces the mortality rate in SARS-CoV2 infected patients [35]. Traditional medicines not only 
work by inhibiting virus replication but also dampen the inflammatory storm by regulating the immune response [35]. Moreover, various studies have clearly specified that phytoconstituents exhibit immunomodulatory properties and are known to augment the expression level of antiinflammatory cytokines along with reducing the expression of inflammatory cytokines such as IL-6, IL-17, and TNF$\alpha$ that are produced during inflammatory conditions [36]. In the present review, we thus enlist some of the important traditional plants that exhibit both anti-inflammatory and tissues protective activities with an idea of employing these plants as a mode of phytotherapy for the treatment of COVID-19 pathologies (Figs. 3,4) \& (Table 1). We have also enlisted some of the clinical trials undergoing with traditional medicines and natural compounds (Table 2).

\subsection{Withania somnifera (Ashawagandha)}

Withania somnifera belongs to Solanaceae family and is commonly known as "Indian Ginseng” or "Indian Winter cherry". It is also known as "Sattvic Kapha Rasayana” that holds a prominent place in Ayurvedic Rasayana herb [62]. It is among the most esteemed herb of the Indian Ayurvedic system which is prominently used as a Rasayana (tonic) with wide range of health benefits. The pharmacologically active components of $W$. somnifera are alkaloids, steroidal lactones, and saponins [63] that are crucial for imparting these health benefits. Withaferin (WA) is the first withanolides compound that was isolated from the leaves of $W$. somnifera. Withanolides are a group of 28 carbon-containing steroidal lactones isolated from solanaceous plant. Along with anti-microbial activity, antiarthritic activity and anti-tumorigenic activity, these withanolides also possess hepato-protective properties [64].

\subsubsection{Anti-viral potential of Withania somnifera}

In addition to several beneficial and health promoting effects, W. Somnifera root extract also possesses anti-viral and immunomodulatory properties as treatment of PBMCs from HIV patients with W. Somnifera reduced the expression of CD38 on $\mathrm{CD}^{+} \mathrm{T}$ cells of HIV patients. CD38 is a marker of $\mathrm{CD}^{+}{ }^{+} \mathrm{T}$ cells and can be used as a biomarker for monitoring HIV progression [65]. It also plays a vital role in chikungunya virus clearance from the host [66]. Recently, Balkrishna et al. demonstrated that withanone from the $W$. somnifera exhibits the ability to weaken the interconnections between SARS-CoV-2 Sprotein RBD (receptor binding domain) and host ACE2 receptor by disrupting the electrostatic interactions between the complex [67]. Proteases are found to be the predominant target for inhibiting the viral replication. One of the best targets for coronavirus is main protease $\left(\mathrm{M}^{\text {pro }}\right) . \mathrm{M}^{\text {pro }}$ cleaves polyproteins required for the replication and transcription of SARS-CoV-2 and inhibition of $\mathrm{M}^{\text {pro }}$ will prevent viral multiplication. A study reported by Shree et al. via molecular docking analysis revealed that two compo-

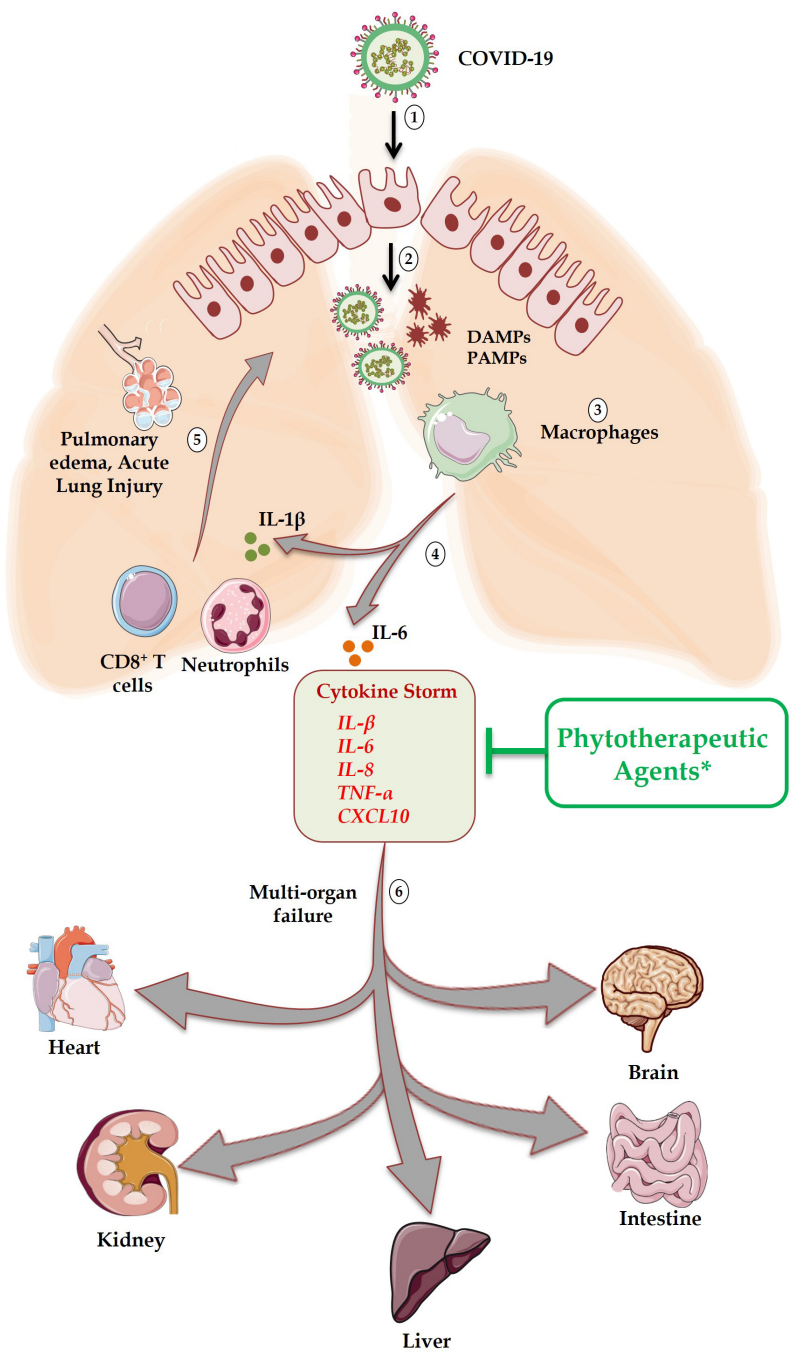

Fig. 3. Schematic representation of immune response and associated tissues toxicity in sequential manner. Step 1: Internalization of COVID19 into target cells expressing ACE2 receptor; Step 2: After pyroptosis waning cells generate death associated molecular patterns (DAMPs) and pathogen associated molecular patterns (PAMPs); Step 3: Virally derived DAMPs and PAMPs engulfed by macrophages in turn produce proinflammatory cytokines; Step 4: Interleukin (IL)-1 $\beta$, IL-6, tumor necrosis factor (TNF)- $\alpha$, chemokine (CC) ligand-2,CCL-3 and CXCL10; Step 5: Recruitment of neutrophils and CD8+ T cells to the site of infection that further produces reactive oxygen species, ROS, MMPs, leukotriene that causes tissue injury in lung parenchyma; Step 6: “Cytokine Storm Syndrome” i.e. flooding of cytokines into circulation that leads to multi-organ failure. *All the 16 traditional medicines systematically summarized in the present review possess anti-inflammatory potential along with proven heart, liver, brain, lung, kidney, intestinal etc. protective activities. (Figure illustrated with the help of https://smart.servier.com/).

nents of $W$. somnifera viz. Withanoside V $(10.32 \mathrm{kcal} / \mathrm{mol})$ and Somniferine $(9.62 \mathrm{kcal} / \mathrm{mol})$ possess high affinity towards SARS-CoV-2 $\mathrm{M}^{\text {pro }}$ (main protease: a vital target for COVID-19) [68]. In consistence with this, a study observed that amongst the forty constituents of $W$. somnifera, Withanoside $\mathrm{V}$ is a potent inhibitor of $\mathbf{M}^{\text {pro }}$ involved in the 
Table 1. Traditional medicines possessing anti-inflammatory and anti-viral properties.

\begin{tabular}{|c|c|c|c|c|c|c|c|}
\hline $\begin{array}{l}\text { Phytotherapeutic } \\
\text { agents }\end{array}$ & Common names & Family & Biologically active components & Pharmacological activities & $\begin{array}{l}\text { Predicted targets in } \\
\text { COVID-19 }\end{array}$ & Tissue protective activities & Ref. \\
\hline Commiphora wightii & $\begin{array}{l}\text { Gugal, Guggul, } \\
\text { Indian Bdellium }\end{array}$ & Burseraceae & $\begin{array}{l}\text { Guggulsteron, lignans, ketosterols, } \\
\text { flavanones, guggulipid }\end{array}$ & $\begin{array}{l}\text { Anti-inflammatory ( } \downarrow \text { IL-1 } \beta \text {, IL-6, TNF- } \alpha \text { ), } \\
\text { Anti-diabetic, Anti-arthritic, Anti-oxidant, Anti- } \\
\text { bronchitis, Anti-viral }\end{array}$ & $\begin{array}{l}\text { Cytokine storm (IL- } \\
1 \beta \text {, IL-6, TNF- } \alpha \text { ) }\end{array}$ & $\begin{array}{l}\text { - Neuroprotective, Cardiopro- } \\
\text { tective, Hepatoprotective, } \\
\text { Nephroprotective, Lung pro- } \\
\text { tective }\end{array}$ & [37] \\
\hline Salvia officinalis & Sage & Lamiaceae & $\begin{array}{l}\text { Alkaloids, phenolic compounds, } \\
\text { steroids polyacetylen, essential oils }\end{array}$ & $\begin{array}{l}\text { Anti-inflammatory ( } \downarrow \text { IL-1 } \beta \text {, IL-6), Anti-cancer, } \\
\text { Anti-diabetic, Anti-microbial, Anti-oxidant }\end{array}$ & $\begin{array}{l}\text { Cytokine storm (IL- } \\
1 \beta, \text { IL-6) }\end{array}$ & $\begin{array}{l}\text { - Neuroprotective, Cardiopro- } \\
\text { tective, Lung protective }\end{array}$ & $-[38]$ \\
\hline Foeniculum vulgre & Fennel & Apiaceae & Coumarins & Anti-inflammatory ( $\downarrow$ IL-17), Anti-oxidant & $\begin{array}{l}\text { Inflammatory cy- } \\
\text { tokine (IL-17) }\end{array}$ & $\begin{array}{l}\text { - Lung protective, Skin protec- } \\
\text { tive }\end{array}$ & $-[39,40]$ \\
\hline Mentha balsamea & Peppermint & Lamiaceae & $\begin{array}{l}\text { Ursolic acid (triterpenoid com- } \\
\text { pound), phenolic acids (rosmarinic } \\
\text { and caffeic acids), flavones, fla- } \\
\text { vanones }\end{array}$ & $\begin{array}{l}\text { Anti-inflammatory ( } \downarrow \text { IL-1 } \beta \text {, IL-6, TNF- } \alpha \text { ), } \\
\text { Anti-viral, Anti-oxidant, Anti-microbial, anti- } \\
\text { carcinogenic }\end{array}$ & $\begin{array}{l}\text { Cytokine storm (IL- } \\
1 \beta, \text { IL-6, TNF- } \alpha \text { ) }\end{array}$ & $\begin{array}{l}\text { - Skin protective, Improve lung } \\
\text { function }\end{array}$ & {$[41,42]$} \\
\hline Salvia rosmarinus & Rosemary & Lamiaceae & Carnosic acid, Carnosol, & $\begin{array}{l}\text { Anti-inflammatory ( } \downarrow \text { IL- } 1 \beta, \downarrow \text { NF-kB pathway, } \\
\text { iNOS), Anti-oxidant, Anti-osteoporotic, Anti- } \\
\text { carcinogenic }\end{array}$ & $\begin{array}{l}\text { IL- } 1 \beta \text {, iNOS in alveo- } \\
\text { lar macrophages, NF- } \\
\text { kB pathway }\end{array}$ & $\begin{array}{l}\text { - Lung protective, Neuroprotec- } \\
\text { - tive }\end{array}$ & \\
\hline Echinacea purpurea & Cone flower & Asteraceae & $\begin{array}{l}\text { Phylloxanthobilins (tetrapyrrolic } \\
\text { compounds), caffeic acids }\end{array}$ & $\begin{array}{l}\text { Anti-inflammatory, Anti-bacterial, Anti-oxidant, } \\
\text { Anti-Diabetic, Treat upper respiratory illness, } \\
\text { Common cold, Anti-viral, Immunomodulatory } \\
\text { properties ( } \uparrow \mathrm{CD} 4^{+} \text {and CD } 8^{+} \mathrm{T} \text { cells) }\end{array}$ & $\begin{array}{l}\text { Lymphopenia } \\
\text { creased CD4 }{ }^{+} \\
\left.\text {CD8 }^{+} \text {T cells }\right)\end{array}$ & $\begin{array}{l}\text { Lung protective, Hepatoprotec- } \\
\text { tive, Neuroprotective }\end{array}$ & $-[45-49]$ \\
\hline Sambucus nigra & Elderberry & Adoxaceae & $\begin{array}{l}\text { Phenolic acids, flavonols, } \\
\text { flavonoids, Total phenols }\end{array}$ & $\begin{array}{l}\text { Anti-inflammatory ( } \downarrow \text { IL-1 } \beta \text {, IL-6, TNF- } \alpha \text {, } \\
\text { COX2, iNOS), Anti-viral, Treat upper respira- } \\
\text { tory illness, Anti-microbial, Anti-pyretic, diuretic } \\
\text { agent, Anti-diabetic, Anti-oxidant properties }\end{array}$ & $\begin{array}{l}\text { Cytokine storm (IL- } \\
1 \beta \text {, IL-6, TNF- } \alpha \text { ), } \\
\text { iNOS and COX-2 in } \\
\text { alveolar macrophages }\end{array}$ & $\begin{array}{l}\text { - Lung protective, Hepatoprotec- } \\
\text { tive, Nephroprotective }\end{array}$ & $-[50-52]$ \\
\hline Panax ginseng & Man-root & Araliaceae & $\begin{array}{l}\text { Ginsenosides, Panax notoginseng } \\
\text { saponin (PNS) }\end{array}$ & $\begin{array}{l}\text { Immunomodulatory properties ( } \uparrow \text { humoral and } \\
\text { cell mediated immunity), Anti-inflammatory } \\
\text { ( } \downarrow \text { IL-8, IL-6; inhibits NF-kB signalling pathway) } \\
\text { Anti-diabetic, Anti-neurotoxic, Anti-angiopathy }\end{array}$ & $\begin{array}{l}\text { Cytokine storm (IL- } \\
1 \beta \text {, IL-6, IL-8, TNF- } \\
\alpha \text { ), NF-kB pathway }\end{array}$ & $\begin{array}{l}\text { - Neuroprotective, Myocardial } \\
\text { - protection, Hepatoprotective, } \\
\text { Intestinal protection, Lung } \\
\text { protective }\end{array}$ & [53-55] \\
\hline Taraxacum officinale & Dandelion & Asteraceae & Polysaccharide, Taraxasterol & $\begin{array}{l}\text { Anti-inflammatory ( } \downarrow \text { IL-1 } \beta, \text { IL-6, TNF- } \alpha \text { ), } \\
\text { Ameliorates colitis ( } \downarrow \text { IL-6/STAT3 pathway), } \\
\text { Anti-arthritic, Anti-viral }\end{array}$ & $\begin{array}{l}\text { Cytokine storm (IL- } \\
1 \beta \text {, IL-6, IL-8, TNF- } \\
\alpha \text { ), NF-kB pathway, } \\
\text { IL-6/STAT3 pathway }\end{array}$ & $\begin{array}{l}\text { - Hepatoprotective, Lung protec- } \\
\text { - tive, Neuroprotective, Nephro- } \\
\text {, protective }\end{array}$ & \\
\hline Tanacetum vulgare & Tansy & Asteraceae & Flavonoids & $\begin{array}{l}\text { Anti-inflammatory ( } \downarrow \text { iNOS and cytokine induced } \\
\text { neutrophil chemo attractants), Anti-microbial } \\
\text { Anti-viral }\end{array}$ & $\begin{array}{l}\text { Cytokine storm (IL- } \\
1 \beta \text {, IL-6, IL-8, TNF- } \\
\alpha \text { ), iNOS }\end{array}$ & $\begin{array}{l}\text { - Nephroprotective, } \\
\text { - tective }\end{array}$ & - [59-61] \\
\hline
\end{tabular}


Table 2. Clinical trials of natural compounds for COVID-19 management and treatment.

\begin{tabular}{|c|c|c|c|c|}
\hline Drug & Composition & Clinical trial phase/type of study/No. of participants & Mechanism of action & $\begin{array}{l}\text { Reference iden- } \\
\text { tifier }\end{array}$ \\
\hline $\begin{array}{l}\text { ArtemiC (Micellar } \\
\text { formulation) }\end{array}$ & $\begin{array}{l}\text { Artemisinin (6 mg), Curcumin } \\
\text { (20 mg), Frankincense (15 mg), } \\
\text { Vitamin C (60 mg) }\end{array}$ & $\begin{array}{l}\text { Phase II/ To evaluate the safety and efficacy of } \\
\text { ArtemiC on patients diagnosed with COVID-19/50 P }\end{array}$ & $\begin{array}{l}\text { Diminish IL-6 and } \\
\text { TNF- } \alpha \text { levels }\end{array}$ & NCT04382040 \\
\hline Previfenon ${ }^{\circledR}$ & $\begin{array}{l}\text { Epigallocatechin-3-Gallate } \\
\text { (EGCG) }(250 \mathrm{mg})\end{array}$ & $\begin{array}{l}\text { Phase II/ To determine the efficacy of Previfenon }{ }^{\circledR} \\
\text { (EGCG) to prevent COVID-19/524 P }\end{array}$ & $\begin{array}{l}\text { Exhibits anti-viral } \\
\text { chemoprophylaxis of } \\
\text { COVID-19 }\end{array}$ & NCT04446065 \\
\hline Guduchi Ghan Vati & Giloy (500 mg) & $\begin{array}{l}\text { NA/ To evaluate the safety and efficacy of Guduchi } \\
\text { Ghan Vati for COVID-19 asymptomatic patients/18- } \\
75 \text { years age }\end{array}$ & $\begin{array}{l}\text { Immunomodulatory } \\
\text { potential }\end{array}$ & NCT04480398 \\
\hline Gargles (Mouthwash) & Neem & $\begin{array}{l}\text { NA/ To reduce intraoral viral load in COVID-19 in- } \\
\text { fected patients/50 P }\end{array}$ & Anti-viral & NCT04341688 \\
\hline Omega 3 Viruxide & Neem oil \& Wort oil & $\begin{array}{l}\text { NA/ To study the viruxal oral and nasal spray for treat- } \\
\text { ing the symptoms of COVID-19/128 P }\end{array}$ & $\begin{array}{l}\text { Reduce symptoms as- } \\
\text { sociated with COVID- } \\
19 \text { infection }\end{array}$ & NCT04357990 \\
\hline $\begin{array}{l}\text { Nigella sativa (Black } \\
\text { Cumin) }\end{array}$ & Black seed (500 mg) & $\begin{array}{l}\text { Phase II/ To study Nigella sativa As a treatment option } \\
\text { for patients having upper respiratory infection caused } \\
\text { by SARS-CoV-2/200 P }\end{array}$ & NA & NCT04401202 \\
\hline $\begin{array}{l}\text { Nigella sativa (HNS- } \\
\text { COVID-PK) }\end{array}$ & Cumin seed powder (1 gm) & $\begin{array}{l}\text { Phase III / Role of honey and Nigella sativa in the } \\
\text { management of COVID-19/30 P }\end{array}$ & NA & NCT04347382 \\
\hline $\begin{array}{l}\text { Traditional Chinese } \\
\text { medicine }\end{array}$ & NA & $\begin{array}{l}\text { Phase III/ To evaluate the safety and efficacy of TCM } \\
\text { as an adjuvant for the patients with SARS-CoV-2 } \\
\text { COVID-19/50 P }\end{array}$ & NA & NCT04323332 \\
\hline $\begin{array}{l}\text { Individualized } \\
\text { Ayurveda }\end{array}$ & Ginger/Turmeric/Honey/Lemon & $\begin{array}{l}\text { NA/ Ayurveda self-management for flu like symp- } \\
\text { toms during the COVID-19 outbreak/18-6 years age }\end{array}$ & 一 & NCT04345549 \\
\hline
\end{tabular}

NA* denotes Not Available at clinical trial government site (https://clinicaltrials.gov/).

replication of SARS-CoV-2 [69]. Furthermore, in silico study demonstrated that withaferin A, a pharmacological constituent of $W$. somnifera displayed strong interaction with the $\mathrm{M}^{\text {pro }}(-11.242 \mathrm{kcal} / \mathrm{mol})$ and with the RNA Dependent RNA Polymerases enzyme (-9.27 kcal/mol) [70]. In case of SARS-CoV, it has been observed that papain like proteases (PLpro) stimulates oxidative stress by inducing ROS production and TGF- $\beta 1$ signaling that further leads to lung fibrosis [71]. A study revealed that W. somnifera exhibits the potential of suppressing generation of oxidative stress induced due to viral infection [72]. Also, among various withanolides, withanolide_D and withanolide_G showed higher binding affinity with PLpro whereas withanolide_M showed better binding with 3CLpro and spike protein. In comparison to all these withanolides, withanolide_Q was found to modulate higher number of proteins [73]. In addition to ACE-2 receptor, SARS-CoV-2 invades human cell by recognizing Glucose-Regulated Protein 78 (GRP78) receptor through its substrate binding domain (SBD). Interestingly, it has been observed that withanolide A also showed higher binding affinity with GRP78 $(-8.7 \mathrm{kcal} / \mathrm{mol})$. Thus, these studies suggest that $W$. somnifera can be potential candidate for treating COVID-19 infected patients. But further research is needed to validate these in silico studies against COVID-19.
5.1.2 Anti-inflammatory and health mediated properties of Withania somnifera

Entry of SARS-CoV-2 virus into the host cells cause development of cytokine storm that involves excessive production of inflammatory cytokines which further results in pulmonary edema and acute lung injury which may results in shock and multiple organ failure eventually leading to death in COVID-19 infected patients. Of note, $W$. somnifera reported to suppress various pro-inflammatory cytokines viz. IL-2, IL-6, TNF- $\alpha$, IFN- $\gamma$, IFN- $\gamma$ protein 10 (IP-10): this condition is interrelated with the improvement in the health condition associated with COVID-19 infection due to cytokine storm [72]. It has also been observed that treatment with $W$. somnifera reduced the oxidative stress, improved endothelial dysfunction, suppressed inflammation and inverted the pulmonary vascular remodelling related to pulmonary hypertension [74]. In consistence with this study, it has also been found that methanolic extracts isolated from roots of $W$. somnifera exerted hepatoprotective role by suppressing inflammation induced secretion of IL- $1 \beta$, TNF- $\alpha$, induced nitric oxide synthase (iNOS) and cyclooxygenase-II (COX-II) [75]. Withaferin A administration also attenuated the LPS induced lung injury by reducing the infiltration of neutrophils into the lungs which is further accompanied with the lowering of inflammatory cytokines viz. IL-6 and TNF- $\alpha$ and oxidative stress [76]. The 
anti-inflammatory properties of water extract of Ashawagandha (ASH-WEX) were investigated under both in vitro and in vivo conditions in LPS induced neuro-inflammatory rat model. It was observed that after 8 weeks of administration, water extract of Ashawagandha ameliorated the inflammatory condition by suppressing the production of inflammatory cytokines viz. IL- $1 \beta$, IL-6, and TNF- $\alpha$ by inhibiting Nuclear factor kappa B (NF- $\kappa$ B), P38 and mitogen activated protein kinase (MAPKs) signaling pathway $[77,78]$. WA treatment suppressed the activation of the nucleotide binding domain leucin rich repeat (NLRP3) inflammasome that further inhibited the IL- $1 \beta$ secretion in LPS induced macrophages and also suppressed the Helicobacter pylori stimulated production of IL- $1 \beta$ from dendritic cells by modulating NLRP-3 inflammasome and NF- $\kappa$ B activation in a dose dependent manner [79]. Thus, based on these studies it can be suggested that $W$. somnifera and its biological active phytoconstituents possess the ability to suppress inflammation and oxidative stress linked with various inflammatory diseases including viral diseases such as COVID-19.

\subsection{Tinospora cordifolia (Guduchi)}

Tinospora cordifolia commonly named as "Guduchi” belongs to Menispermaceae family. Across the globe, this traditional herb has gained researcher's interest because of its diverse medicinal properties e.g., antioxidant, anti-arthritic, anti-diabetic, anti-inflammatory, anti-malarial, anti-stress, anti-allergic and immunomodulatory etc. [80]. The biologically active components of Guduchi responsible for its medicinal properties are alkaloids, aliphatic, glycosides, steroids and diterpenoid lactones [81].

\subsubsection{Anti-viral potential of Tinospora cordifolia}

Recently, in silico study screened the anti-viral potential of chemical constituents of Tinospora cordifolia (e.g., berberine $\left(\mathrm{C}_{20} \mathrm{H}_{18} \mathrm{NO}_{4}\right)$, choline $\left(\mathrm{C}_{5} \mathrm{H}_{14} \mathrm{NO}\right), \beta$ sitosterol $\left(\mathrm{C}_{29} \mathrm{H}_{50} \mathrm{O}\right)$, tetrahydropalmatine $\left(\mathrm{C}_{21} \mathrm{H}_{25} \mathrm{NO}_{4}\right)$ and octacosanol $\left(\mathrm{C}_{28} \mathrm{H}_{58} \mathrm{O}\right)$ against SARS-CoV-2 [82]. Among all the screened chemical constituents, molecular docking along with molecular dynamics studies revealed that berberine regulates the $\mathrm{M}^{\text {pro }}$ protein function and thus inhibits the viral replication [82]. Furthermore, a study by Balkrishna et al. demonstrated that one of the phytocompounds of T. cordifolia "Tinocordiside" significantly reduced the electrostatic interaction between ACE2-RBD complexes that leads to enhancement in the flexibility of the complex [83]. Thus, we can postulate that Tinocordiside could be one of the viable options for controlling the SARS-CoV-2 entry into the host cell. In consistent to this, a study reported that four natural compounds isolated from T. cordifolia that are Berberine, Isocolumbin, Magnoflorine and Tinocordiside showed higher binding efficacy with key SARS-CoV-2 targets that are responsible for attachment of virus to host cell such as surface glycoprotein (6VSB) and receptor binding domain (6MoJ) [84]. In addition, these natural compounds also showed higher binding efficacy with the targets that are responsible for replication of virus into the host cell such as RNA dependent RNA polymerase (6M71) and with main protease (6Y84) [84]. Hence, these studies highlight the merit of using natural compounds isolated from T. cordifolia in the clinical management of infection caused by SARS-CoV-2. Interestingly, another study reported that administration of Tinospora cordifolia along with other ayurvedic herbs strengthens and rejuvenates the immune system of the SARS-CoV-2 exposed asymptomatic group [85]. Guduchi Ghan Vati is under clinical trials for managing and treatment of COVID-19 (NCT04480398). Tinospora cordifolia silver nanoparticles (AgNPs) at 250 $\mathrm{ug} / \mathrm{mL}$ concentration enhanced the viability of chikungunya virus infected cells [86] and thus indicated towards the usage of this plant in AgNPs form as an anti-viral agent that could provide a plausible alternative treatment against SARS-CoV-2 which has no known antiviral therapy and vaccine available yet.

5.2.2 Anti-inflammatory and health mediated properties of Tinospora cordifolia

The anti-inflammatory properties of Tinospora cordifolia extract (TCE) is mediated via suppression of proinflammatory cytokines such as IL- $1 \beta$, IL-6, IL-17 and TNF- $\alpha$ in LPS induced Raw 264.7 macrophages, neuroinflammatory rat model and in arthritis model [87-89]. The polysaccharide G1-4A from Tinospora cordifolia shows anti-microbial activity by inhibiting the survival of both drug sensitive as well as multiple drug resistant Mycobacterium tuberculosis (MTB) strains under both in vitro and in vivo conditions through the modulation of the host immune system in a TLR4-dependent manner [89, 90]. Thus, these studies suggest that Tinospora cordifolia exhibits anti-viral and anti-inflammatory properties.

\subsection{Glycyrrhiza glabra (Yashtimadhu)}

Glycyrrhiza glabra belongs to Fabaceae family and is commonly known as Liquorice or Licorice. Since, 1950s one of the triterpene glycosides called Glycyrrhizin (GL) isolated from Glycyrrhiza glabra (root and rhizomes) has been studied widely because of its pharmacological properties such as anti-inflammatory, hepatoprotective, anti-carcinogenic and anti-viral properties.

\subsubsection{Anti-viral potential of Glycyrrhiza glabra}

In addition to various health promoting effects of Glycyrrhiza glabra, it also possesses anti-viral activities: GC7 (18 $\beta$-glycyrrhetinnic acid), a primary metabolite of GL was assessed by $\mathrm{Fu}$ et al. in which they mentioned that this metabolite targets the nuclear proteins of Ebola and MARS virus [91]. As ACE2 is a part of renin-angiotensin-aldosterone-system (RAAS) and the compounds that inhibits classical ACE leads to activation 
of plasma aldosterone and aldosterone receptor (MR) system. Further MR activation protects the organs from attachment of COVID-19 by reducing the ACE2 expression. Murck et al. study reported that a systematically active metabolite of GL i.e., glycyrrhetinic acid (GA) inhibits the $11 \beta$-hydroxysteroid dehydrogenase (11 $\beta$-HSD2) and activates MR in the organs including lungs [92]. GA it's selfpossesses anti-inflammatory potential by targeting toll like receptor (TLR)-4 and also found to block TMPRSS2 and thus inhibits virus uptake. Thus, this study suggested that GL reduced the severity associated with COVID-19 infection by acting at two stages: it blocks the virus entry by reducing the expression of TMPRSS2 and ACE2 and also reduced the lung inflammation independent of ACE2 [92]. Furthermore, an in vitro study suggested that GL potently neutralize the SARS-CoV-2 virus by inhibiting the main viral protease [93]. Thus, highlighted that GL should be investigated for COVID-19. In addition to this, clinical trials (NCT044241349, NCT043465887, NCT04487964) study suggested that glycyrrhizin showed synergistic effect with spironolactone (SP) and may be considered for COVID-19 infections [94]. Another biologically active ingredient of Glycyrrhiza glabra root is Glycyrrhizic acid (GA). Recently, a study revealed that glycoside moiety of GA displayed efficient binding with the HMG box protein HMGB1 that plays a vital role in the virus infection and replication [95]. Further, a study demonstrated that GA, Liquiritigenin (L) and Glabridin (G) active compounds of Glycyrrhiza glabra inhibits the enzymatic activity of $\mathrm{M}^{\text {pro }}$ by binding strongly to the active site. But in comparison to other two compounds GA showed higher binding affinity of $-8.0 \mathrm{Kcal} / \mathrm{mol}$ [96]. Also, GA could be considered as the best molecule of Glycyrrhiza glabra that could be useful against SARS-CoV-2 [97]. Thus, various studies suggested that after consultation with the ayurvedic practitioner, Yashtimadhu can be administered as an immune booster that can play a crucial role in the prevention and management of COVID-19 [98]. Altogether, we can summarize that GL and GA can be deployed as phytotherapeutic agents in ameliorating inflammation and lung injury associated with SARS-CoV-2 infection.

5.3.2 Anti-inflammatory and health mediated properties of Glycyrrhiza glabra

Recently, it is proven that GL mediates antiinflammatory effects by suppressing the levels of inflammatory cytokines (IL- $1 \beta$, IL- 6 and TNF- $\alpha$ ) in BALF of LPS induced ALI mouse model [99]. Flow cytometry and light microscopy data also demonstrated that GL administration reduced the count $/ \mathrm{mL}$ and percentages of infiltrated: total immune cells, neutrophils and macrophages in BALF and lung tissues as compared to LPS group by downregulating the expression of CXCR4/CXCR1 on neutrophils [99]. Similarly, a study demonstrated that GL administration reduced inflammation, pain and lung damage in ALI by downregulating TLR2 signaling pathway [100]. Further, a study reported that GL (at $200 \mathrm{mg} / \mathrm{kg}$ ) downregulated the TLR2 mediated signaling in lung tissue as well in alveolar macrophages in ischemia-reperfusion (I/R) lung injury model [101]. It has been observed that GA administration alleviated the sepsis induced ALI in rats by suppressing inflammatory reaction, oxidative stress and apoptosis in lung tissue by reducing NF- $\kappa \mathrm{B}$, JNK and MAPK signaling pathway [102]. Accordingly, we can conclude that Glycyrrhiza glabra has the potential to be employed as a novel phytotherapeutic agent for ameliorating the inflammation and lung damage associated with infection.

\subsection{Allium sativum (Garlic)}

Allium sativum belongs to Liliaceae family and is commonly known as "Garlic" with a well-established historical relevance as a favorable traditional medicine in the ancient years. Notably, garlic has been in use for the treatment of several conditions such as cardiovascular diseases [103], hyperlipidemia [104] and as anti-fungal [105] or antidiabetic for impediment of nephropathy [106] etc. The biologically active ingredients of garlic that are responsible for its medicinal properties are: sulphur containing compounds like alliin, diallyl-sulfide, diallyl-disulfide, diallyltrisulfide, S-allylcysteine (SAC), enzymes (alliinase) and the compounds produced from alliin (allicin) [107, 108]. Garlic exhibits potent anti-microbial activity due to the production of allicin in damaged garlic tissues which inhibits bacterial infection in vapor form [109]. It also exhibits anti-bacterial and anti-biofilm potential against antibiotic resistant Shiga-Toxin producing Escherichia coli (STEC) isolates from food sources as well as from patient samples [110]. Since no volatile antibiotic is available till date that can treat pulmonary pathogenic infections, allicin could make a valuable addition to the presently available therapies.

\subsubsection{Anti-viral potential of Allium sativum}

Recently, the anti-viral property of garlic essential oil has been investigated by a group in which they examined the anti-coronavirus activity of garlic oil by molecular docking technique and observed that some biologically active ingredients of garlic such as diallyl-disulfide and diallyl-trisulfide have the potential to suppress ACE2 host receptor and main protease PDB6LU7 of SARS-CoV2 virus [111]. Thus, the results suggest that garlic essential oil (GEO) may act as a valuable natural anti-viral source that contributes towards the restricted entry of coronavirus into the human body. A study suggested that Allium sativum possess the potential of reducing inflammatory cytokines and adipose tissue derive hormone i.e., leptin having inflammatory nature and may be utilize as a preventative measure in the population before being infected with COVID19 infection [112]. Organosulfurs and flavonoids are found to be the predominant bioactives behind the immunomod- 
ulatory nature of Allium sativum. By forming the hydrogen bonds with the active sites of serine protease these bioactives may inhibit the COVID-19 outbreak [113]. Furthermore, a study demonstrated that alliin, SAC and other bioactive compounds of Allium sativum, can be employed as a potential inhibitor candidate for COVID-19 and could be beneficial in combating this pandemic [114].

5.4.2 Anti-inflammatory and health mediated properties of Allium sativum

Several in vitro and in vivo studies reported that water fraction of garlic exhibits anti-inflammatory properties by which it ameliorated the infiltration of inflammatory cells, mucus hypersecretion and lung based-goblet formation in allergic asthma mouse model. Moreover, water fraction of garlic enhanced the levels of Th1 cytokines (IL-12 and IFN $\gamma$ ) along with reducing IL-1 $\beta$, IL-6 and TNF- $\alpha$ inflammatory cytokines in BALF [115]. Administration of SAC also protected the LPS induced acute kidney injury (AKI) in C57BL/6 strain of mice via preserving the mitochondrial integrity with simultaneous reduction in oxidative stress, inflammation and apoptosis [116]. Thus, these studies suggested that Allium sativum can be a potential therapeutic candidate for COVID-19 infection.

\subsection{Zingiber officinale (Ginger)}

Zingiber officinale belongs to Zingiberaceae family which is not only utilized as a spice or flavouring agent in food but also considered as a traditional medicine from ancient times. It is adapted as a traditional herb due to its potential to treat various health problems such as nausea [117], migraine [118], diabetes etc. [119, 120]. The biologically active ingredients that are responsible for its pharmacological properties are paradols, 5acetoxy-6-gingerol, gingerdiones, gingerdiols, 6-gingerol, 10-gingerol, 12-gingerol, 6-dehydrogingerols, 6-shogaol and 3,5-diacetoxy-6-gingerdioal. Among all the two primary compounds that are found to be associated with medicinal properties are 6-gingerol and 6-shogaol [121]. It also exhibits anti-microbial [122], anti-inflammatory [123], anti-ageing [124], anti-oxidant [125], neuroprotective [126] and anti-carcinogenic [127, 128, 130, 131] properties. Both hyperoxia and inflammatory conditions cause lung injury that further leads to the progression of broncho-pulmonary dysplasia (BPD) condition.

\subsubsection{Anti-viral potential of Zingiber officinale}

Moreover, it has also been found that ginger essential oil (GEO) constituents also exhibit the virucidal activity [131]. Recently, molecular docking study revealed that rhizome extract of ginger possesses higher affinity for the SARS-CoV-2 papain-like protease (PLpro) which is essential for the survival and replication of SARS-CoV-2 [132]. Recently, in silico study demonstrated that phytochemical compounds of Zingiber officinale showed significant affinity with the S-spike protein of SARS-CoV-2 and
ACE2 receptor in the host and may have a great potential in reducing the viral load along with decreasing the shedding of SARS-CoV-2 in the nasal passage [133]. Hence, it may be of interest to consider garlic for anti-viral therapy.

5.5.2 Anti-inflammatory and health mediated properties of Zingiber officinale

Administration of ginger at a dose $1000 \mathrm{mg} / \mathrm{kg}$ abridged the levels of inflammatory cytokines (IL-1 $\beta$, IL-6 and TNF- $\alpha$ ) and protected the lung from the damage and edema in LPS + hyperoxia mice group [134]. Different fractions of ginger also exhibited the potential to inhibit the migration and activation of monocytes, macrophages and neutrophils [123]. Hence, suggesting that Zingiber officinale possess the potential of treating viral infection by suppressing the inflammation induced upon viral infection.

\subsection{Curcuma longa (Turmeric)}

Curcumin belongs to curcuminoids group that accounts for the majority of fraction of curcuminoids as compared to bisdemethoxycurcumin and demethoxycurcumin. It is also known as diferuloylmethane and found to be the chief polyphenol observed in rhizome of Curcuma longa (Turmeric) and other curcuma species [135]. In the past 50 years, most of the beneficial properties of Curcuma longa are predominantly attributed to curcumin. Curcuma longa has traditionally been used as a medicinal herb for pathological conditions due to its anti-microbial, anti-inflammatory, anti-carcinogenic and anti-oxidant properties.

\subsubsection{Anti-viral potential of Curcuma longa}

Curcumin is also known to possess anti-viral properties against dengue virus (serotype 2) [136], human simplex viruses (HSV) [137], HIV [138], Zika and chikungunya viruses [139]. Moreover, in vitro and in vivo studies revealed that treatment with curcumin ameliorated the influenza virus associated pneumonia by attenuating the lung injury and regulating the levels of inflammatory cytokines in macrophages [140]. Recently, a study discussed the potential ways by which curcumin (poly-phenolic compound) can be employed for treating SARS-CoV-2 infection [141]. Furthermore, docking results suggest that curcumin exhibits the highest interaction with the spike protein (-141.36 $\mathrm{kcal} / \mathrm{mol}$ ) and with the ACE2 receptor (-142.647 kcal/mole) [142]. In consistence with this, a study suggested that curcumin also displayed significant binding with the $\mathrm{M}^{\text {Pro }}$ [143]. Interestingly, with the help of in silico approach researchers evaluated the potential of curcumin in destabilizing the structural integrity of SARS-CoV-2 in combination with hydroxychloroquine [144]. Molecular docking data displayed that binding energy of hydroxychloroquine $(-24.58 \mathrm{kcal} / \mathrm{mol})$ is greater than that of curcumin $(-20.47$ $\mathrm{kcal} / \mathrm{mol}$ ) for main protease. On the other hand, for S protein receptor binding domain, curcumin displayed higher binding energy $(-38.84 \mathrm{kcal} / \mathrm{mol})$ in comparison to hydroxychloroquine $(-35.87 \mathrm{kcal} / \mathrm{mol})$ [144]. Thus, the study sug- 
gested that curcumin can also be used as adjunct drug with hydroxychloroquine for disrupting the structural integrity of the SARS-CoV-2 protein. Altogether, these studies support the potential of curcumin as a promising treatment against viral infections including COVID-19 that mediates its effects by damaging the lung tissues.

5.6.2. Anti-inflammatory and health mediated properties of Curcuma longa

Inflammasomes plays a vital role in maturation and secretion of inflammatory cytokines (IL-1 $\beta$ and IL-18) via NF- $\kappa \mathrm{B}$ signaling pathway. Recently, a study proved that curcumin works as an "inflammasome silencer" [145]. It has been found that curcumin also plays a vital role in various respiratory diseases such as asthma, acute lung injury, chronic obstructive pulmonary disease (COPD) and pulmonary fibrosis that are linked with inflammatory conditions [146, 147]. However, its low or no water solubility results in its poor bioavailability, rapid metabolism, and fast elimination thus lessening its therapeutic efficacy. Recently, it has been observed that nanoencapsulation of curcuminoids isolated from Curcuma longa and liposomal curcumin formulation enhanced its water solubility [148, 149]. Furthermore, a study demonstrated that loading of curcumin on large porous microparticles (LPMPs) showed promising results in the treatment of idiopathic pulmonary fibrosis [150]. Charge of the nanoparticles carrying curcumin plays a key role in regulating the efficiency and cellular uptake of nanoparticles and it was observed that the positively charged nanoparticles have a higher efficiency to enter into alveolar macrophages as compared to negatively or neutral charged nanoparticles [151]. Thus, the studies suggest that curcumin could be used as therapeutic and prophylactic agent in inhibiting the attachment of virus with the host cells.

\subsection{Cinnamon (Dalchini)}

Till date different cinnamon species e.g. Cinnamomum verum, Cinnamomum cassia, Cinnamomum burmanii, Cinnamomum zeylanicum, Cinnamomum tamala, Cinnamomum loureirii and Cinnamomum cordatum have been reported that can be used in food industries as food additives. Cinnamon belongs to Lauraceae family and recently, cinnamon has gained tremendous attention due to its medicinal properties. The pharmacologically active chemical components of cinnamon are: cinnamaldehyde, trans-cinnamaldehyde and cinnamic acid. These active components confer various health benefits when administered adequately including antioxidants, anti-microbial, anti-inflammatory, anti-gastric ulcer, anti-yeast etc. [152].

\subsubsection{Anti-viral potential of Cinnamon}

In most of the viral infections including SARSCoV-2 the expression of HSPA5 protein is upregulated due to ER stress conditions [153]. Interestingly, it has been reported that SARS-CoV-2 with the aid of spike protein en- ters into the host cells by using more than one host cell receptor and among them one of the receptors is HSPA5 also known as Bip or GRP78 [154]. Under stress conditions, HSPA5 is exposed on the cell surface that permits pathogen entry into the cell. Surprisingly, cinnamon administration has been reported to reduce ER stress in rat obesity mouse model [155] thus it is plausible to suggest that cinnamon administration may also inhibit the translocation of HSPA5 to the cell membrane from cytoplasm and reduce the interaction between virus and host cells thereby, inhibiting virus entry. Recently, it has been demonstrated that cinnamon exhibits the potential to bind HSPA5 substrate binding domain $\beta(\operatorname{SBD} \beta)$ with a binding energy $-6.25 \pm 1.10$ and thus it might interfere with SARS-CoV-2 recognition and binding [156]. Furthermore, in silico data validation indicated that two compounds Pavetannin C1 (PAV) and Tenufolin (TEN) among 48 isolates compounds of cinnamon exhibits good binding efficacy with the main proteases and spike proteins of SARS-CoV-2 [157]. Cinnamomum zeylanicum is also one of the components of Ayiush Kwath that exhibits antiinflammatory, anti-oxidant, anti-platelet and hepatoprotective potential that may be effective in controlling COVID19 infection [158].

\subsubsection{Anti-inflammatory and health mediated properties of Cinnamon}

The bark of Cinnamomum verum has well established anti-inflammatory potential and it has been demonstrated that the ethanolic fraction of cinnamon showed antiinflammatory properties by inhibiting the production of IL$1 \beta$, IL-6, TNF- $\alpha$ and nitric oxide (NO) molecules [159]. Also, a study reported in 2018 showed that ethanolic fraction of cinnamon inhibited the LPS induced IL-8 secretion in THP-1 monocytes via modulating TLR-2 and TLR-4 signaling pathway [160]. Thus, cinnamon can be employed as an antidote against natural and chemical toxicities.

\subsection{Moringa oliefera (Drumsticks)}

Moringa oliefera belongs to Moringaceae family and commonly known as drumstick or miracle tree, considered as nature's healthiest and nutritious plant. Its origin is in the northern side of India and its pharmacological properties lie in the different parts of tree such as leaf, bark, sap, roots and flowers that have been utilized as a traditional herb for years [161]. M. oliefera exhibits ethnomedicinal characteristics, attributed to various biologically active ingredients of the plant such as flavonoids, polyphenol, vitamins, tannins, isothiocyanates and saponins [162, 163].

\subsubsection{Anti-viral potential of Moringa oliefera}

Moreover, seeds of the $M$. oliefera have also been utilized as reducing and stabilizing agents for the biosynthesis of silver nanoparticles (AgNP) to fight against dengue virus (DEN-2) and its primary vector Aedes aegypti [164]. Further, leaves of $M$. oliefera tree facilitated the manufacturing of gold nanoparticles that further aided the cancer 
cells recognition and possess anti-proliferative and apoptotic activities [165]. Recently, some evidences suggest that plants not only provide macro and micro-nutrients as food but also deliver distinct molecules with medicinal properties such as microRNAs and developed a phenomenon known as "cross-kingdom regulation" [166]. Thus, it is plausible to suggest that $M$. oliefera being nutritious plants follows this cross-kingdom regulation and modulates the expression of human genes responsible for immunomodulatory properties. Recently, a study attempted to identify the natural compounds from $M$. oliefera that exhibit the potential to inhibit COVID-19 [167]. The molecular docking results suggested that four compounds such as quercetin, kaempferol, morphine and pterygospermin displayed higher binding efficacy with $\mathrm{M}^{\text {pro }}$ and RNA dependent RNA polymerase (RdRp) proteins of SARS-CoV2 [167]. Thus, these data clearly indicate that these four compounds can be a promising candidate for COVID-19 prevention. Further, in silico study confirmed that phytocompounds of $M$. oliefera showed strong interaction with main protease of SARS-CoV-2 and can curtail the replication of SARS-CoV-2 in host cells [168]. Moreover, a study suggested that presence of Anthraquinone phytochemical in M. oliefera may serve as an anti-viral agent against COVID19 [169].

5.8.2 Anti-inflammatory and health mediated properties of Moringa oliefera

Several studies demonstrated that different extracts (alcoholic or aqueous) of $M$. oliefera leaves possess diverse range of biological activities such as immunomodulatory, analgesic, radioprotective, tissue protective (liver, kidney, testes, lungs and heart) and antioxidant properties [162, 170]. In comparison to moringa seed extract (MSE), extract enriched with isothiocyanate showed enhanced anti-inflammatory potential under both in vitro and in vivo conditions making it a promising phytotherapeutic agent [171]. Furthermore, one of the novel polysaccharides (MRP-1) isolated from the roots of $M$. oliefera showed enhanced anti-inflammatory properties by suppressing NO and TNF- $\alpha$ expression in LPS induced inflammation in macrophages. Thus, pointing towards new possible application of M. oliefera [172].

\subsection{Azadirachta indica (Neem)}

Azadirachta indica belongs to Mahogany family, commonly known as Muarubaini; and possess the potential to treat 40 different diseases. Due to its astonishing activities this plant is also known as Heal All, Nature's Drugstore, Village Pharmacy and Panacea [173]. United Nations has declared Neem plant as "Tree of $21^{\text {st }}$ century" and various reports also suggested that this plant is meant for resolving global problems. Neem is also considered to be "storehouse" for more than 300 phytochemicals. Two foremost classes of phytochemicals are isoprenoids and non-isoprenoids. Isoprenoids class includes limonoids, C-secomeliacins, vilasinins, diterpenoids and triterpenoids. Non-isoprenoids class involves coumarin, polyphenolics, sulfur compounds, tannins, aliphatic compounds, polysaccharides, and proteins. Nimbin is a triterpenoid that accounts for the pharmacological activities of neem oil. It exhibits anti-pyretic, anti-inflammatory, antiseptic, anti-histamine, anti-microbial, anti-malarial, anticancer and fungicidal properties [173-175].

\subsubsection{Anti-viral potential of Azadirachta indica}

Recently, using computational and experimental method it has been observed that bioflavonoids of $A$. indica inhibited Dengue virus type-2 (DENV-2) infectivity by interacting with NS2B-NS3; DENV-2 serine viral protease. Further, by using molecular docking, molecular dynamics simulation and binding energy calculations, it was observed that the compounds derived from neem such as Nimbolin A, Nimocin and Cycloartanols displayed stable and efficient binding with the vital regions of $\mathrm{E}$ and $\mathrm{M}$ proteins required for the assembly of SARS-CoV-2 [176]. Moreover, a study revealed that several compounds present in the leaves of neem exhibit the potential to suppress the $\mathrm{M}^{\text {pro }}$ of SARS-CoV-2 [177]. Altogether, these results demonstrated that Neem exhibits multidimensional therapeutic applications and can also be a potential therapeutic option against COVID-19. Recently, a study demonstrated that $A$. indica showed significant inhibitory activity against papain like proteases PLpro of SARS-CoV-2 [178]. Among various compounds, desacetylgedunin (DCG) showed highest binding affinity against PLpro [178]. In consistent to this, a study showed that in comparison to other bioactive compounds of $A$. indica: few compounds viz. Vepnin, Epiazadiradione, Azadiradione and Nimbione compounds showed greater potential to acts as COVID-19 protease inhibitor. Thereby, it is plausible to suggest that neem may acts a potential phytotherapy in COVID-19 pandemic by inhibiting the proteases required for the infectivity and replication of SARS-CoV-2 [179], thereby highlighting the potential of $A$. indica in the development of effective drug against viruses.

5.9.2 Anti-inflammatory and health mediated properties of Azadirachta indica

Furthermore, a study revealed that treatment with neem leaf extract suppressed the infiltration of neutrophils and monocytes along with reduction of IL-6, MCP-1 and TNF- $\alpha$ cytokines in BALF in the lungs of LPS-induced pulmonary inflammatory mice model [180]. Moreover, a study demonstrated that treatment with nimbolide (limonoid) abrogated the difficulties associated with ARDS. Molecular docking studies suggested that nimbolide interacts with TNF- $\alpha$ and hence ameliorated the TNF- $\alpha$-regulated NF$\kappa$ B-histone deacetylases 3 (HDAC3) crosstalk in LPS induced ARDS [181]. These reports thus suggest towards the usage of neem in treating chronic pulmonary diseases. A study showed that nimbolide ameliorated colitis in Dextran Sodium Sulfate (DSS) induced mice model by suppressing 
the NF- $\kappa \mathrm{B}$ mediated inflammatory signalling pathway in macrophages and intestinal epithelial cells [182].

\subsection{Ocimum tenuiflorum/sanctum (Tulsi)}

Ocimum tenuiflorum belongs to Lamiaceae family and is commonly known as holy basil or Tulsi. Within Ayurveda this plant is known as "The Queen of Herbs" and "Mother Medicine of Nature". Various scientific studies till date have examined the medicinal properties of tulsi under both in vitro and in vivo conditions. These studies demonstrated that tulsi has unique blend of actions such as antiinflammatory, anti-stress, anti-cancer, anti-microbial, antioxidant, anti-ulcer, anti-thyroid, adaptogenic, anti-cataract etc. [183].

\subsubsection{Anti-viral potential of Ocimum tenuiflorum/sanctum}

Furthermore, it has been found that different fractions of $O$. tenuiflorum (crude extract, polyphenol and terpenoid) exhibited anti-viral properties against avian influenza H9N2 infection [184]. Molecular docking studies have proved that several phytochemicals isolated from $O$. sanctum showed anti-viral activity by interacting with proteins involved in viral replication and metabolic pathways of H1N1 influenza virus [185]. Anti-viral based cytopathic effects (CPE) studies showed that methanolic extracts of $O$. sanctum inhibited the cell death of Vero E6 cells infected with DENV-1 serotype [186]. Moreover, molecular modelling studies revealed that natural products derived from $O$. sanctum leaves possess inhibitory activity against ribonuclease- $\mathrm{H}$ and DNA polymerase activity of Reverse Transcriptase (RT) enzyme of HIV [187]. Recently, a study via in silico approach showed that flavonoids and polyphenolic compounds predominantly luteolin-7-Oglucuronide and chlorogenic acid, exhibits the ability to covalently bind to the main protease of SARS-CoV-2 and results in irreversible inhibition of viral enzyme [188]. Moreover, a study suggested that Ocimum sanctum extract bioactive compounds viz. tulsinol showed significant interaction with the ACE2 receptor, main proteases and papain like proteases [189]. Thus, these studies suggests that Ocimum sanctum can be employed as a preventative measure against COVID-19 due to its inherent potential to inhibit virus entry, virus replication etc.

5.10.2 Anti-inflammatory and health promoting properties of Ocimum tenuiflorum/sanctum

A study revealed that leaf extract of $O$. tenuiflorum and its phenolic compound eugenol attenuated the activation of human monocyte THP1 cells by suppressing the LPS induced IL-6, MIP- $1 \alpha$, MCP-1 and TNF- $\alpha$ secretion and also block the NF- $\kappa \mathrm{B}$ translocation from cytoplasm to nuclei [190]. O. sanctum also showed lung and brain protective effects against smoke aggravated pulmonary and brain damage in rats by suppressing smoke induced oxidative stress [191, 192].

\subsection{Camellia sinensis (Green tea)}

Camellia sinensis belongs to Theaceae family and is commonly known as green tea. Tea is one of the widely used beverages worldwide and mainly comprises of minerals, vitamins, carbohydrates, polyphenols, caffeine, and theanine [193]. Among other polyphenols, catechins and flavonols are found to be the predominant constituents. Further, catechins include epicatechin (EC), epigallocatechin (EGC), gallocatechin (GC), epicatechin gallate (ECG), gallocatechin gallate (GCG), and epigallocatechin gallate (EGCG). Green tea exhibits various health benefits against different diseases such as diabetes, obesity, cancer, cardiovascular diseases, neurodegenerative disorders etc. [193, 194].

\subsubsection{Anti-viral potential of Camellia sinensis}

Furthermore, Zhou et al. stated that SARS-CoV2 infected patients are prone towards secondary infections that lead to multi-organ failure [3]. Interestingly, a study showed that administration of L-theanine alleviated the organ damage in sepsis induced liver and kidney injury mice model in a dose dependent manner [195]. Catechin polyphenol also known to exhibit anti-viral properties against HIV, influenza virus, herpes simplex virus type-1 and hepatitis B and C viruses [155, 196]. In order to investigate the anti-viral potential of Camellia sinensis against coronavirus, a recent study demonstrated that EGCG displayed higher binding energy $(-8.3 \mathrm{kcal} / \mathrm{mol})$ with $\mathrm{M}^{\text {pro }}$ of SARS-CoV-2 in comparison to remdesivir $(-7.1 \mathrm{kcal} / \mathrm{mol})$ and chloroquine $(-5.8 \mathrm{kcal} / \mathrm{mol})$ [197]. Further, molecular docking analysis revealed that five bioactive polyphenols of Camellia sinensis viz. theaflavin, epigallocatechin 3-gallate, genistein, 1-O-caffeoylquinic acid and ethyl transcaffeate showed affinity against matrix metalloproteinase (MMPs) against SARS-CoV-2 main protease [198]. Among these five polyphenolic compounds, theaflavin and epigallocatechin 3-gallate showed strong affinity and good drug likeness score and could be beneficial option in the prophylaxis of COVID-19 outbreak [198]. In consistent to this, a similar study suggested that EGCG and theaflavin mainly theaflavin-3, 3'-digallate (TF3) showed significant interaction with the receptor binding domain of SARSCoV-2 [199]. Also, tea component Thearubigins showed strong affinity against SARS-CoV-2 $3 \mathrm{CL}^{\text {pro }}$ protease and it suggests that Camellia sinensis can halt replication cycle and thus, can be a potential therapeutic option against SARS-CoV-2 infection [200]. Furthermore, a study suggested that Camellia sinensis is a vital source of nutritional immunity which can increase innate immunity and mitigate the COVID-19 pandemic and disease progression [201].

5.11.2 Anti-inflammatory and health mediated properties of Camellia sinensis

Remarkably, various animal and human studies showed that EGCG (predominant catechins); possess anti- 
inflammatory potential [202, 203]. A study reported that pre-treatment with theanine $(20 \mathrm{mg} / \mathrm{kg} /$ day) (bioactive component of green tea leaves) suppressed the LPS induced secretion of IL- $1 \beta$, IL-6, and TNF- $\alpha$ along with enhancing the IL-10/IFN- $\gamma$ ratio in the liver of mice [204]. Furthermore, administration of theanine also alleviated the LPS induced C-reactive proteins and iNOS in liver tissues [204]. Thus, ameliorated inflammation in LPS induced acute liver injury mice model. Recently, a study reported that treatment with green tea extract attenuated inflammation in the colon tissues by supressing $\mathrm{NF}-\kappa \mathrm{B}$ signaling pathway and restored the gut-integrity in DSS induced colitis mice model [205]. It also exhibits pre-biotic properties and administration of green tea extract enhanced the abundance of beneficial bacteria (Bifidobacterium and Faecalibaculum) along with reducing the abundance of harmful bacteria (Mucispirillum and Bacteroids) in colitis model [205].

\subsection{Astragalus membranaceus (Huangqi)}

Astragalus is an important traditional herb in Chinese medicine. Primarily, it is used as a lung protective tonic that enhances resistance against pulmonary infections. From in vitro studies, it was observed that treatment with Astragalus augmented the cytotoxic T cells function; B cells proliferation, activation and antibody mediated responses [206]. Various studies till date have reported antiviral properties of Astragalus polysaccharide (APS) against viruses [207, 208].

\subsubsection{Anti-viral potential of Astragalus membranaceus}

A study reported that in case of COVID-19, endoplasmic reticulum (ER) stress plays a crucial role in the upregulation of receptors required for SARS-CoV-2 adherence to the host cells. Remarkably, it has been observed that APS attenuated porcine circovirus type 2 (PCV2) infections by inhibiting ER stress both in vitro and in vivo [209] thereby highlighting the significance of APS consumption in limiting virus entry into the host cells through the inhibition of ER stress. These studies therefore clearly highlight the potential of Astragalus in the management of SARS-CoV-2 mediated pathologies. Recent studies have shown that multiple organ failure that occurs during COVID-19 infection results from the enhancement in inflammatory cytokine storm and accumulation of free radicals. A study revealed that Astragalus membranaceus exhibits anti-inflammatory property and suppressed the activation of MAPK/NF- $\kappa$ B signaling pathway and downregulated the levels of inflammatory cytokines such as IL-6, IL8 and TNF- $\alpha$ and thus, reduced the inflammatory response. One of the biological active compounds of Astragalus membranaceus i.e. Astragaloside IV activated the PI3K/Akt signaling pathway and enhanced the levels of superoxide dismutase (SOD) and protected the body.
5.12.2 Anti-inflammatory and health mediated properties of Astragalus membranaceus

A study showed that treatment with APS suppressed the replication of avian infectious bronchitis coronavirus in chicken embryo kidney (CEK) cells by reducing the expression of inflammatory cytokines (IL-1, IL-6, IL-8, TNF- $\alpha$ ) [207]. Further, it has been reported that APS promoted immunity and exerted anti-tumorigenic property by modulating TLR4 mediated MyD88 dependent signalling pathway [210, 211]. Recently, a study revealed that it ameliorated the Salmonella typhimurium induced inflammation in diarrhea mice model by balancing the GUT flora of mice that maintains the intestinal integrity by enhancing the tight junction proteins viz. Claudin-1 and Occludin [212]. Moreover, a study demonstrated that total flavonoid astragalus (TFA) extracts attenuated LPS elicited inflammation in Raw 264.7 macrophages by reducing MAPK and NF- $\kappa$ B signalling pathway [213]. A study has reported that treatment with astragaloside, an active component of Astragalus membranaceus inhibited the IL- $1 \beta$ induced generation of inflammatory mediators such as prostaglandin E2 (PGE2), IL-6, TNF- $\alpha$ and MMP-13 in patient derived chondrocytes and osteoarthritis mouse model [214]. Thus, we can propose that astragaloside may act as a potential therapeutic agent in the treatment of various inflammatory diseases. Moreover, it has been shown that consumption of dried root of Astragalus protected various organs such as kidney, liver, heart, lungs, intestine and brain from oxidative stress mediated injury in various mice models [215, 216]. Recently, few studies reported that usage of Astragalus membranaceus with other anti-oxidative compounds enhanced the immunomodulatory potential of Astragalus [217-219].

\subsection{Piper longum (Pippali)}

Piper longum belongs to Piperaceae family, commonly known as long pepper (pippali). Piperlongumine (PL) an amide compound extracted from the roots of $P$. longum, is a biologically active component known for its medicinal properties. It possesses various physiological and pharmacological properties such as anti-tumorigenic, anti-inflammatory, anti-depressant, analgesic, sedative etc. [220-222].

\subsubsection{Anti-viral potential of Piper longum}

Recently a study demonstrated that piperolactam A from $P$. longum shows higher affinity for $\mathrm{M}^{\text {pro }}$ and ACE2 receptor [223]. It has been observed that by targeting these proteins, piperolactam A blocks the replication and entry of virus into the host cells [223].

5.13.2 Anti-inflammatory and health mediated properties of Piper longum

Recently, a study revealed that pre-treatment with PL suppressed the OVA induced airway inflammation in asthma mouse model. PL administration inhibits inflam- 
matory reaction in both BALF and lung tissue by suppressing the infiltration of inflammatory cells and $\mathrm{T}_{H} 2$ cytokine levels involved in IgE production by reducing NF- $\kappa \mathrm{B}$ mediated inflammatory pathway in asthma model [224, 225]. In continuity to this, a study reported that treatment with PL significantly reduced the lipopolysaccharide (LPS) induced inflammatory genes expression (IL-6, TNF- $\alpha$, iNOS) in BV2 microglial cells by inhibiting NF- $\kappa$ B signaling pathway [226]. Thus, these evidences suggest that PL could be a potential agent in treating various inflammatory diseases. Generally, macrophages are categorized under two extremities: M1 macrophages (pro-inflammatory) and M2 macrophages (anti-inflammatory) and dramatic shifts in the cell metabolism pathways regulate the phenotype and functions of M1 and M2 macrophages [227]. Interestingly, a study demonstrated that PL exhibits the potential to suppress glycolysis via suppression of hexokinase activity [228]. It also reduces the glucose levels, influx of lymphocytes, macrophages, and neutrophils in BALF and attenuates both systemic and pulmonary inflammation [229]. A study reported that hypoxia condition can potentiate the activity of PL [230]. Thus, these findings suggest that PL exhibits the potential to eradicate viral infection by modulating the inflammatory potential of alveolar macrophages via altering the metabolic profile of these cells under hypoxic conditions observed in case of COVID-19 patients.

\subsection{Phyllanthus emblica (Amla)}

Phyllanthus emblica or Emblica officinalis belongs to Phyllanthaceae family and is commonly known as Indian gooseberry. The fruits are utilized widely in Ayurvedic medicine as a potent "Rasayana" and also found to be the major component of the Ayurvedic preparation “Chyawanprash” [231, 232]. Increasing evidences suggest that $P$. emblica extract (PEE) possess lung protective activities.

\subsubsection{Anti-viral potential of Phyllanthus emblica}

Recently, a study demonstrated that various chemical constituents of Phyllanthus emblica such as phyllaemblicin-B, phyllaemblinol and phyllaemblicin G7 exhibited higher binding affinity against helicase and spike proteins of SARS-CoV-2 [233]. In case of SARS, MERS and SARS-CoV-2 virus, 3-chymotrypsin like cysteine proteases $\left(3 \mathrm{CL}^{\text {pro }}\right)$ enzyme regulates their replication and life cycle. A study demonstrated that (2S)-Eriodictyol 7O-(6"-O-galloyl)-beta-D-glucopyranoside phytochemical from Phyllanthus emblica displayed strong binding affinity with $3 C^{\text {pro }}(-19.47 \mathrm{kcal} / \mathrm{mol})$ enzyme. Thus, altogether these studies prove that Phyllanthus emblica may be a potential therapeutic candidate for COVID-19 treatment [234].
5.14.2 Anti-inflammatory and health mediated properties of Phyllanthus emblica

Studies showed that administration of PE extract protected the lung from the inflammatory injury by altering the IL-1 $\beta /$ miR-i101/Lin28B signaling pathway [235]. It also inhibited the benzopyrene induced pre-cancerous lung lesions by downregulating the pro-inflammatory cytokine expression viz. IL- $1 \beta$, IL-6, TNF- $\alpha$ and MIP-2 in lung tissues. It also suppressed edema in rats in a dose dependent manner [236].

\section{Concluding remarks and future outlook}

In the present review, we have summarized the pharmacological potential of various traditional medicines that can be employed for the management and treatment of cytokine storm induced in COVID-19. Phytotherapeutic agents play a vital role in the prevention and treatment of several diseases including viral diseases. Traditional plants having medicinal properties are used as foremost resources for alternative medicine including several modern medicines for the treatment of various human disorders including chronic inflammatory conditions. The traditional medicines are also found to be effective in treating various viral infections. The scientific society has already proven the efficacy of various plants harboring anti-viral potential for such conditions and also accomplished relevant position for them in the health care system across the globe for both human and animals. Currently, there are no proven treatment options available for the deadly acute respiratory distress syndrome caused by SARS-CoV-2 virus. Various countries including India and China have already resorted to their respective traditional medicine for the management of COVID-19 pandemic which has been of great help in alleviating various symptoms leading to reduced mortality associated with the viral infection. In April 2020, China approved the usage of three traditional herbs (Liahuaqingwen, Jinhuaqinggan and Xuebijing) in treating mild and severe cases of COVID-19 [237]. However, when we employ them with antibiotics, anti-virals and immunosuppressive drugs; safety should be cautiously monitored. Several in silico studies have also proven the relevance of traditional medicines in inhibiting the viral entry, virus replication and assembly (Figs. 4,5). A study demonstrated that EGYVIR (herbal drug comprised of black pepper and curcumin) antagonize the NF- $\kappa \mathrm{B}$ signaling pathway and abrogated the release of inflammatory cytokines viz. IL-6 and TNF- $\alpha$ under SARS-CoV-2 infected Huh-7 cell line [238]. Taken together, more evidences and clinical trials are further warranted for the judicious use of traditional herbs in the treatment of COVID-19. 


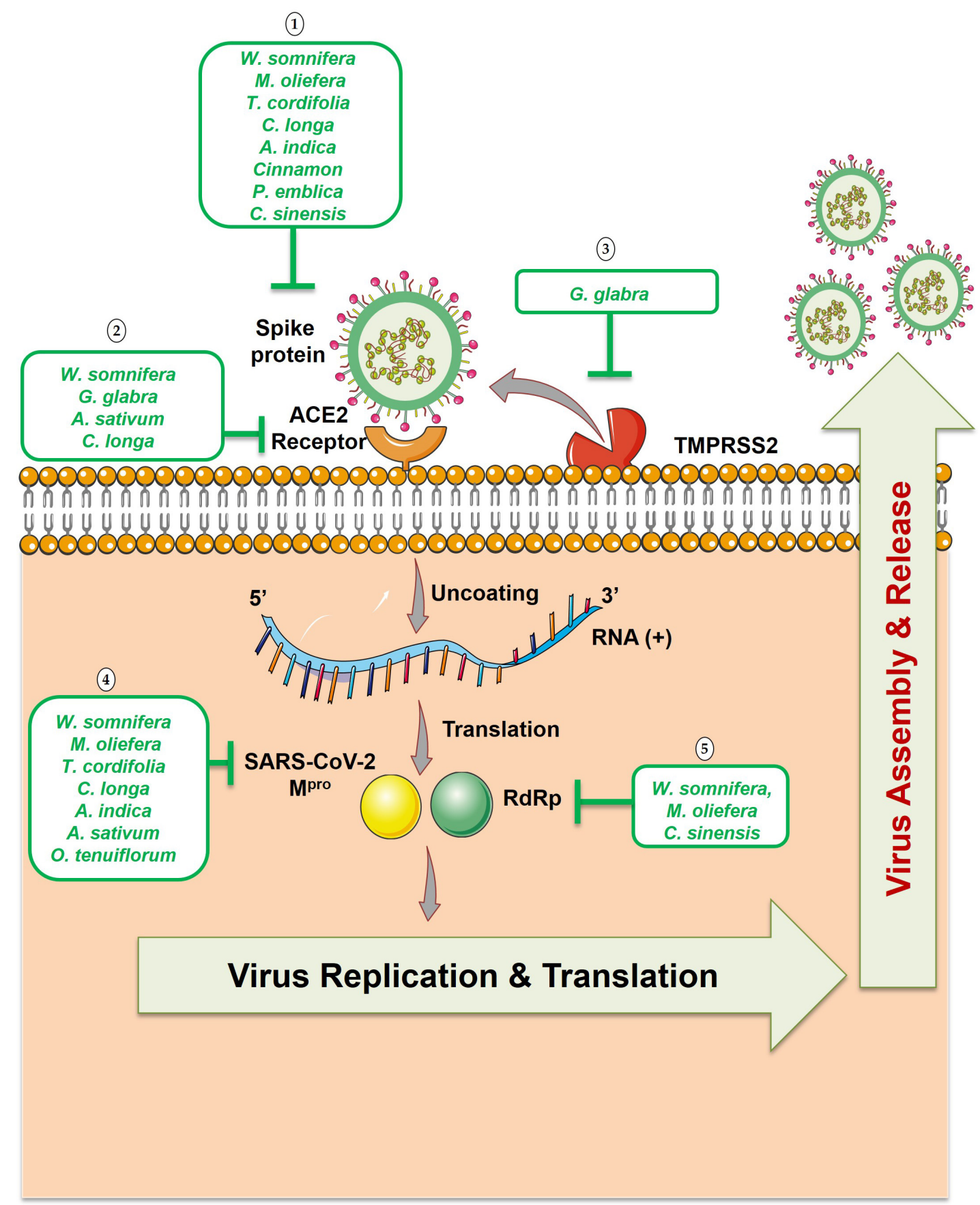

Fig. 4. Potential phytotherapeutic approaches against SARS-CoV-2. (1) Natural compounds that targets spike proteins could block SARS-CoV-2 from interacting with the ACE2 receptor. (2) Natural compounds that targets ACE2 host receptor could block SARS-CoV-2 attachment to the cells. (3) Natural compounds against the serine protease (TMPRSS2) prevent the spike protein cleavage which is required for the viral fusion to the host cells. (4) Natural compounds that targets $\mathrm{M}^{\text {pro }}$ Main protease) could block the replication and translation of viral genome. (5) Natural compounds that hinders RdRp (RNA Dependent RNA Polymerase) activity leads to blockage of viral positive sense (+) single stranded RNA replication (Figure illustrated with the help of https://smart.servier.com/).

\section{Author contributions}

RKS conceptualized and wrote the manuscript. LS drafted and revised the manuscript. AB, ZA, DM, BV and SR provided valuable suggestions during manuscript preparation and critically revised the manuscript. RKS suggested and LS created the illustrations.

8. Ethics approval and consent to participate Not Applicable. 


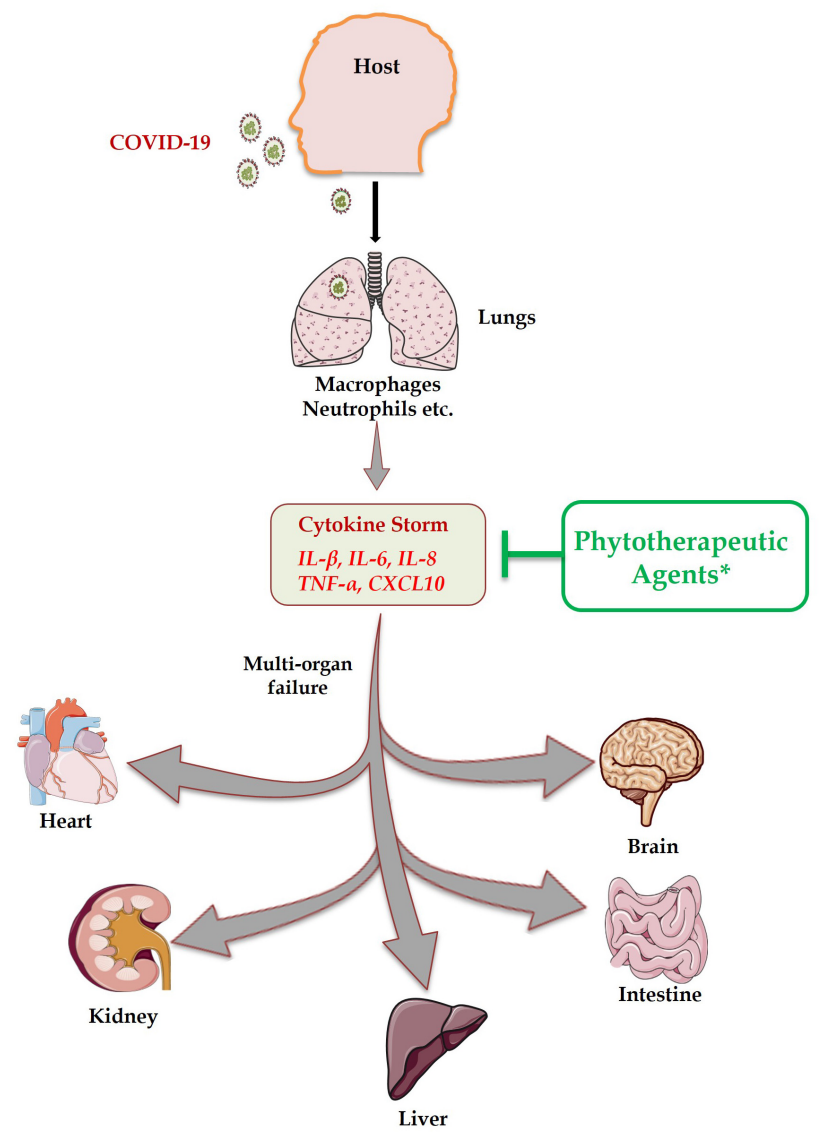

Fig. 5. Transmission of COVID-19 occurs mainly from one person to other through droplets during sneezing and coughing, touching contaminated surfaces, personal contacts etc. After entering host, it attacks the lung tissue and results in massive production of inflammatory cytokines (Cytokine Storm Syndrome) that in turn causes multi-organ failure. Phytotherapeutic agents exhibit the potential to suppress inflammatory cytokines along with tissue protective properties.

\section{Acknowledgment}

LS and ZA thank UGC for research fellowship, AB thank DST SERB project for research fellowship and DM thanks CSIR for research fellowship.

\section{Funding}

This work was financially supported by projects: DST-SERB (EMR/2016/007158), Govt. of India and intramural project from All India Institute of Medical Sciences (AIIMS) (A-596, AI-15), New Delhi-India sanctioned to RKS. LS, ZA, AB, DM, BV, SR and RKS acknowledge the Department of Biotechnology, AIIMS, New Delhi-India for providing infrastructural facilities.

\section{Conflict of interest}

The authors declare no conflicts of interest.

\section{References}

[1] Zhou P, Yang X, Wang X, Hu B, Zhang L, Zhang W, et al. A pneumonia outbreak associated with a new coronavirus of probable bat origin. Nature. 2020; 579: 270-273.

[2] Menachery VD, Yount BL, Sims AC, Debbink K, Agnihothram SS, Gralinski LE, et al. SARS-like WIV1-CoV poised for human emergence. Proceedings of the National Academy of Sciences of the United States of America. 2016; 113: 3048-3053.

[3] Zhou F, Yu T, Du R, Fan G, Liu Y, Liu Z, et al. Clinical course and risk factors for mortality of adult inpatients with COVID19 in Wuhan, China: a retrospective cohort study. The Lancet. 2020; 395: 1054-1062.

[4] Mehta P, McAuley DF, Brown M, Sanchez E, Tattersall RS, Manson JJ. COVID-19: consider cytokine storm syndromes and immunosuppression. The Lancet. 2020; 395: 1033-1034.

[5] Xu H, Zhong L, Deng J, Peng J, Dan H, Zeng X, et al. High expression of ACE2 receptor of 2019-nCoV on the epithelial cells of oral mucosa. International Journal of Oral Science. 2020; 12: 8.

[6] Diao B, Wang C, Tan Y, Chen X, Liu Y, Ning L, et al. Reduction and functional exhaustion of $\mathrm{T}$ cells in patients with coronavirus disease 2019 (COVID-19). Frontiers in Immunology. 2020; 11; 827.

[7] Huang C, Wang Y, Li X, Ren L, Zhao J, Hu Y, et al. Clinical features of patients infected with 2019 novel coronavirus in Wuhan, China. The Lancet. 2020; 395; 497-506.

[8] Guan W, Ni Z, Hu Y, Liang W, Ou C, He J, et al. Clinical characteristics of coronavirus disease 2019 in China. The New England Journal of Medicine. 2020; 382: 1708-1720.

[9] Rothe C, Schunk M, Sothmann P, Bretzel G, Froeschl G, Wallrauch C, et al. Transmission of 2019-nCoV infection from an asymptomatic contact in Germany. The New England Journal of Medicine. 2020; 382: 970-971.

[10] Thompson BT, Chambers RC, Liu KD. Acute respiratory distress syndrome. The New England Journal of Medicine. 2017; 377: 562-572.

[11] Wu C, Chen X, Cai Y, Xia J, Zhou X, Xu S, et al. Risk factors associated with acute respiratory distress syndrome and death in patients with coronavirus disease 2019 pneumonia in Wuhan, China. JAMA Internal Medicine. 2020; 180: 934.

[12] Singh TU, Parida S, Lingaraju MC, Kesavan M, Kumar D, Singh RK. Drug repurposing approach to fight COVID-19. Pharmacological Reports. 2020; 72: 1479-1508.

[13] Chen L, Xiong J, Bao L, Shi Y. Convalescent plasma as a potential therapy for COVID-19. The Lancet Infectious Diseases. 2020; 20: 398-400.

[14] Wang C, Xie J, Zhao L, Fei X, Zhang H, Tan Y, et al. Alveolar macrophage dysfunction and cytokine storm in the pathogenesis of two severe COVID-19 patients. EBioMedicine. 2020; 57: 102833.

[15] Fehr AR, Perlman S. Coronaviruses: an overview of their replication and pathogenesis. Methods in Molecular Biology. 2015; 1282: 1-23.

[16] Wong CK, Lam CWK, Wu AKL, Ip WK, Lee NLS, Chan IHS, et al. Plasma inflammatory cytokines and chemokines in severe acute respiratory syndrome. Clinical and Experimental Immunology. 2004; 136: 95-103.

[17] Zhang B, Zhou X, Qiu Y, Song Y, Feng F, Feng J, et al. Clinical characteristics of 82 cases of death from COVID-19. PLoS ONE. 2020; 15: e0235458-e0235458.

[18] Guan W, Liang W, Zhao Y, Liang H, Chen Z, Li Y, et al. Comorbidity and its impact on 1590 patients with COVID-19 in China: a nationwide analysis. European Respiratory Journal. 2020; 55: 2000547.

[19] Hoffmann M, Kleine-Weber H, Schroeder S, Krüger N, Herrler $\mathrm{T}$, Erichsen S, et al. SARS-CoV-2 cell entry depends on ACE2 and TMPRSS2 and is blocked by a clinically proven protease inhibitor. Cell. 2020; 181: 271-280.e8. 
[20] Daly JL, Simonetti B, Klein K, Chen KE, Williamson MK, Antón-Plágaro C, et al. Neuropilin-1 is a host factor for SARSCoV-2 infection. Science. 2020; 370: 861-865.

[21] Suba Z. Prevention and therapy of COVID-19 via exogenous estrogen treatment for both male and female patients. Journal of Pharmaceutical Sciences. 2020; 23: 75-85.

[22] V Taneja. Sex hormones determine immune response. Frontiers in Immunology. 2018; 9: 1931.

[23] Srivastava RK, Dar HY, Mishra PK. Immunoporosis: immunology of osteoporosis-role of $\mathrm{T}$ cells. Frontiers in Immunology. 2018; 9: 657.

[24] Dar HY, Azam Z, Anupam R, Mondal RK, Srivastava RK. Osteoimmunology: the Nexus between bone and immune system. Frontiers in Bioscience. 2018; 23: 464-492.

[25] Channappanavar R, Fett C, Mack M, Ten Eyck PP, Meyerholz DK, Perlman S. Sex-based differences in susceptibility to severe acute respiratory syndrome coronavirus infection. Journal of Immunology. 2017; 198: 4046-4053.

[26] Jones VG, Mills M, Suarez D, Hogan CA, Yeh D, Segal JB, et al. COVID-19 and Kawasaki disease: novel virus and novel case. Hospital Pediatrics. 2020; 10: 537-540.

[27] Colaco S, Chhabria K, Singh D, Bhide A, Singh N, Singh A, et al. A single-cell RNA expression map of coronavirus receptors and associated factors in developing human embryos. 2020. (in press)

[28] Wan S, Yi Q, Fan S, Lv J, Zhang X, Guo L, et al. Characteristics of lymphocyte subsets and cytokines in peripheral blood of 123 hospitalized patients with 2019 novel coronavirus pneumonia (NCP). 2020. (in press)

[29] Li H, Liu L, Zhang D, Xu J, Dai H, Tang N, et al. SARS-CoV-2 and viral sepsis: observations and hypotheses. The Lancet. 2020; 395: 1517-1520

[30] Chen X, Zhao B, Qu Y, Chen Y, Xiong J, Feng Y, et al. Detectable serum SARS-CoV-2 viral load (RNAaemia) is closely associated with drastically elevated interleukin 6 (IL-6) level in critically ill COVID-19 patients. 2020. (in press)

[31] Tan L, Wang Q, Zhang D, Ding J, Huang Q, Tang YQ, et al. Lymphopenia predicts disease severity of COVID-19: a descriptive and predictive study. Signal Transduction and Targeted Therapy. 2020; 5: 33

[32] Hamming I, Timens W, Bulthuis MLC, Lely AT, Navis GJ, van Goor H. Tissue distribution of ACE2 protein, the functional receptor for SARS coronavirus. A first step in understanding SARS pathogenesis. The Journal of Pathology. 2004; 203: 631637.

[33] Feng Z; Diao B; Wang R; Wang G; Wang C; Tan Y; et al. The novel severe acute respiratory syndrome coronavirus 2 (SARSCoV-2) directly decimates human spleens and lymph nodes. 2020. (in press)

[34] Liu J, Li S, Liu J, Liang B, Wang X, Wang H, et al. Longitudinal characteristics of lymphocyte responses and cytokine profiles in the peripheral blood of SARS-CoV-2 infected patients. EBioMedicine. 2020; 55: 102763.

[35] Ren J, Zhang AH, Wang XJ. Traditional Chinese medicine for COVID-19 treatment. Pharmacological Research. 2020; 155: 104743.

[36] Srivastava RK. Phytoconstituents as novel osteo-protective agents implications in bone health. Frontiers in Bioscience. 2020; 25: 1259-1296.

[37] Kunnumakkara AB, Banik K, Bordoloi D, Harsha C, Sailo BL, Padmavathi G, et al. Googling the Guggul (Commiphora and Boswellia) for prevention of chronic diseases. Frontiers in Pharmacology. 2018; 9: 686.

[38] Ghorbani A, Esmaeilizadeh M. Pharmacological properties of Salvia officinalis and its components. Journal of Traditional and Complementary Medicine. 2017; 7: 433-440.

[39] Yang IJ, Lee DU, Shin HM. Anti-inflammatory and antioxidant effects of coumarins isolated from Foeniculum vulgare in lipopolysaccharide-stimulated macrophages and
12-O-tetradecanoylphorbol-13-acetate-stimulated mice. Immunopharmacology and Immunotoxicology. 2015; 37: 308-317.

[40] Zhang S, Chen X, Devshilt I, Yun Q, Huang C, An L, et al. Fennel main constituent, trans-anethole treatment against LPSinduced acute lung injury by regulation of Th17/Treg function. Molecular Medicine Reports. 2018; 18: 1369-1376.

[41] Chang C, Fu J, Su C, Yin M, Hsu Y. Four spices prevent mice from contracting Salmonella enterica serovar Typhimurium. Experimental and Therapeutic Medicine. 2019; 18: 2956-2964.

[42] Zerin T, Lee M, Jang WS, Nam K, Song H. Anti-inflammatory potential of ursolic acid in Mycobacterium tuberculosissensitized and Concanavalin a-stimulated cells. Molecular Medicine Reports. 2016; 13: 2736-2744.

[43] Schwager J, Richard N, Fowler A, Seifert N, Raederstorff D. Carnosol and related substances modulate chemokine and cytokine production in macrophages and chondrocytes. Molecules. 2016; 21: 465.

[44] Keshavarzi Z, Shakeri F, Barreto GE, Bibak B, Sathyapalan T, Sahebkar A. Medicinal plants in traumatic brain injury: neuroprotective mechanisms revisited. BioFactors. 2019; 45: 517535.

[45] Aarland RC, Bañuelos-Hernández AE, Fragoso-Serrano M, Sierra-Palacios EDC, Díaz de León-Sánchez F, Pérez-Flores LJ, et al. Studies on phytochemical, antioxidant, anti-inflammatory, hypoglycaemic and antiproliferative activities of Echinacea purpurea and Echinacea angustifolia extracts. Pharmaceutical Biology. 2017; 55: 649-656.

[46] Sharifi-Rad M, Mnayer D, Morais-Braga MFB, Carneiro JNP, Bezerra CF, Coutinho HDM, et al. Echinacea plants as antioxidant and antibacterial agents: from traditional medicine to biotechnological applications. Phytotherapy Research. 2018; 32: 1653-1663.

[47] Karg CA, Wang P, Vollmar AM, Moser S. Re-opening the stage for Echinacea research-characterization of phylloxanthobilins as a novel anti-oxidative compound class in Echinacea purpurea. Phytomedicine. 2019; 60: 152969.

[48] Vimalanathan S, Schoop R, Suter A, Hudson J. Prevention of influenza virus induced bacterial superinfection by standardized Echinacea purpurea, via regulation of surface receptor expression in human bronchial epithelial cells. Virus Research. 2017; 233: 51-59.

[49] Park S, Lee M, Jung S, Lee S, Kwon O, Kreuter MH, et al. Echinacea purpurea protects against restraint stress-induced immunosuppression in BALB/c mice. Journal of Medicinal Food. 2018; 21: 261-268.

[50] Porter RS, Bode RF. A review of the antiviral properties of black elder (Sambucus nigra L.) products. Phytotherapy Research: PTR. 2017; 31: 533-554.

[51] Hawkins J, Baker C, Cherry L, Dunne E. Black elderberry (Sambucus nigra) supplementation effectively treats upper respiratory symptoms: a meta-analysis of randomized, controlled clinical trials. Complementary Therapies in Medicine. 2019; 42: 361365.

[52] Viapiana A, Wesolowski M. The phenolic contents and antioxidant activities of infusions of Sambucus nigra L. Plant Foods for Human Nutrition. 2017; 72: 82-87.

[53] He L, Ren J, Liu R, Chen Q, Zhao J, Wu X, et al. Ginseng (Panax ginseng Meyer) oligopeptides regulate innate and adaptive immune responses in mice via increased macrophage phagocytosis capacity, NK cell activity and Th cells secretion. Food \& Function. 2017; 8: 3523-3532.

[54] Bai L, Gao J, Wei F, Zhao J, Wang D, Wei J. Therapeutic potential of ginsenosides as an adjuvant treatment for diabetes. Frontiers in Pharmacology. 2018; 9: 423.

[55] Zhang J, Li Q, Shao Q, Song J, Zhou B, Shu P. Effects of panax notoginseng saponin on the pathological ultrastructure and serum IL-6 and IL-8 in pulmonary fibrosis in rabbits. Journal of Cellular Biochemistry. 2018; 119: 8410-8418. 
[56] Chen W, Fan H, Liang R, Zhang R, Zhang J, Zhu J. Taraxacum officinale extract ameliorates dextran sodium sulphate-induced colitis by regulating fatty acid degradation and microbial dysbiosis. Journal of Cellular and Molecular Medicine. 2019; 23: 8161-8172.

[57] Sang R, Yu Y, Ge B, Xu L, Wang Z, Zhang X. Taraxasterol from Taraxacum prevents concanavalin a-induced acute hepatic injury in mice via modulating TLRs/NF-kB and Bax/Bc1-2 signalling pathways. Artificial Cells, Nanomedicine, and Biotechnology. 2019; 47: 3929-3937.

[58] Flores-Ocelotl MR, Rosas-Murrieta NH, Moreno DA, VallejoRuiz V, Reyes-Leyva J, Domínguez F, et al. Taraxacum officinale and Urtica dioica extracts inhibit dengue virus serotype 2 replication in vitro. BMC Complementary and Alternative Medicine. 2018; 18: 95.

[59] Mazzio EA, Li N, Bauer D, Mendonca P, Taka E, Darb M, et al. Natural product HTP screening for antibacterial (E.coli 0157:H7) and anti-inflammatory agents in (LPS from E. coli O111:B4) activated macrophages and microglial cells; focus on sepsis. BMC Complementary and Alternative Medicine. 2016; 16: 467.

[60] Mazzio EA, Bauer D, Mendonca P, Taka E, Soliman KF. Natural product HTP screening for attenuation of cytokine-induced neutrophil chemo attractants (CINCs) and NO2- in LPS/IFN $\gamma$ activated glioma cells. Journal of Neuroimmunology. 2017; 302: 10-19.

[61] Álvarez ÁL, Habtemariam S, Abdel Moneim AE, Melón S, Dalton KP, Parra F. A spiroketal-enol ether derivative from Tanacetum vulgare selectively inhibits HSV-1 and HSV-2 glycoprotein accumulation in Vero cells. Antiviral Research. 2015; 119: 818.

[62] Changhadi GS. Ashwagandharishta-Rastantra Sar Evam Sidhyaprayog Sangrah. Krishna-Gopal Ayurveda Bhawan. 1938; 743-774.

[63] Mishra LC, Singh BB, Dagenais S. Scientific basis for the therapeutic use of Withania somnifera (ashwagandha): a review. Alternative Medicine Review. 2000; 5: 334-346.

[64] Budhiraja R, Krishan P, Sudhir S. Biological activity of withanolides. Journal of Scientific and Industrial Research. 2000; 59: 904-911.

[65] Maurya SP, Das BK, Singh R, Tyagi S. Effect of Withania somnifer on CD38 expression on CD8+ T lymphocytes among patients of HIV infection. Clinical Immunology. 2019; 203: 122124.

[66] Jain J, Narayanan V, Chaturvedi S, Pai S, Sunil S. In vivo evaluation of Withania somnifera-based Indian traditional formulation (Amukkara Choornam), against Chikungunya virusinduced morbidity and arthralgia. Journal of Evidence-Based Integrative Medicine. 2018; 23: 2156587218757661.

[67] Balkrishna A, Pokhrel S, Singh J, Varshney A. Withanone from Withania somnifera may inhibit novel coronavirus (COVID-19) entry by disrupting interactions between viral S-protein receptor binding domain and host ACE2 receptor. 2020. (in press)

[68] Shree P, Mishra P, Selvaraj C, Singh SK, Chaube R, Garg N, et $a l$. Targeting COVID-19 (SARS-CoV-2) main protease through active phytochemicals of ayurvedic medicinal plants-Withania somnifera (Ashwagandha), Tinospora cordifolia (Giloy) and Ocimum sanctum (Tulsi)-a molecular docking study. Journal of Biomolecular Structure and Dynamics. 2020; 1-14.

[69] Tripathi MK, Singh P, Sharma S, Singh TP, Ethayathulla AS, Kaur P. Identification of bioactive molecule from Withania somnifera (Ashwagandha) as SARS-CoV-2 main protease inhibitor. Journal of Biomolecular Structure and Dynamics. 2020; 1-14.

[70] Pandit M, Latha N. In silico studies reveal potential antiviral activity of phytochemicals from medicinal plants for the treatment of COVID-19 infection. 2020; 1-38. (in press)

[71] Kashyap VK, Dhasmana A, Yallapu MM, Chauhan SC, Jaggi $\mathrm{M}$. Withania somnifera as a potential future drug molecule for COVID-19. Future Drug Discovery. 2020; 2: FDD50.
[72] Mandlik (Ingawale) DS, Namdeo AG. Pharmacological evaluation of Ashwagandha highlighting its healthcare claims, safety, and toxicity aspects. Journal of Dietary Supplements. 2020; 18 : 183-226.

[73] Khanal P, Patil BM, Pasha I, Dey YN, Chand S. Withanolides from Withania somnifera as an immune booster and their therapeutic option against COVID-19. Research Square. 2021. (in press)

[74] Kaur G, Singh N, Samuel SS, Bora HK, Sharma S, Pachauri $\mathrm{SD}$, et al. Withania somnifera shows a protective effect in monocrotaline-induced pulmonary hypertension. Pharmaceutical Biology. 2015; 53: 147-157.

[75] Devkar ST, Kandhare AD, Zanwar AA, Jagtap SD, Katyare SS, Bodhankar SL, et al. Hepatoprotective effect of withanolide-rich fraction in acetaminophen-intoxicated rat: decisive role of TNF$\alpha$, IL-1 $\beta$, COX-II and iNOS. Pharmaceutical Biology. 2016; 54 : $2394-2403$.

[76] Gao S, Li H, Zhou X, You J, Tu D, Xia G, et al. Withaferin a attenuates lipopolysaccharide-induced acute lung injury in neonatal rats. Cellular and Molecular Biology. 2015; 61: 102-106.

[77] Gupta M, Kaur G. Withania somnifera as a potential anxiolytic and anti-inflammatory candidate against systemic lipopolysaccharide-induced neuroinflammation. Neuromolecular Medicine. 2018; 20: 343-362.

[78] Gupta M, Kaur G. Withania somnifera (L.) Dunal ameliorates neurodegeneration and cognitive impairments associated with systemic inflammation. BMC Complementary and Alternative Medicine. 2019; 19: 217.

[79] Kim J, Lee J, Kang M, Jeong Y, Choi J, Oh S, et al. Withaferin a inhibits helicobacter pylori-induced production of IL- $1 \beta$ in dendritic cells by regulating NF- $\mathrm{kB}$ and NLRP3 inflammasome activation. Immune Network. 2015; 15: 269-277.

[80] Sharma U, Bala M, Kumar N, Singh B, Munshi RK, Bhalerao S Immunomodulatory active compounds from Tinospora cordifolia. Journal of Ethnopharmacology. 2012; 141: 918-926.

[81] Upadhyay AK, Kumar K, Kumar A, Mishra HS. Tinospora cordifolia (Willd.) Hook. f. and Thoms. (Guduchi)-validation of the Ayurvedic pharmacology through experimental and clinical studies. International Journal of Ayurveda Research. 2010; 1: 112-121.

[82] Chowdhury P. In silico investigation of phytoconstituents from Indian medicinal herb 'Tinospora cordifolia (giloy)' agains SARS-CoV-2 (COVID-19) by molecular dynamics approach. Journal of Biomolecular Structure and Dynamics. 2020; 1-18.

[83] Balkrishna A, Pokhrel S, Varshney A. Tinocordiside from Tinospora cordifolia (Giloy) may curb SARS-CoV-2 contagion by disrupting the electrostatic interactions between host ACE2 and viral S-protein receptor binding domain. Combinatorial Chemistry \& High Throughput Screening. 2020; 23.

[84] Sagar V, Kumar AHS. Efficacy of natural compounds from Tinospora cordifolia against SARS-CoV-2 protease, surface glycoprotein and RNA polymerase. Research Square. 2021. (in press)

[85] Rastogi S, Pandey DN, Singh RH. COVID-19 pandemic: a pragmatic plan for ayurveda intervention. Journal of Ayurveda and Integrative Medicine. 2020; 579

[86] Sharma V, Kaushik S, Pandit P, Dhull D, Yadav JP, Kaushik S. Green synthesis of silver nanoparticles from medicinal plants and evaluation of their antiviral potential against chikungunya virus. Applied Microbiology and Biotechnology. 2019; 103: 881-891.

[87] Sannegowda KM, Venkatesha SH, Moudgil KD. Tinospora cordifolia inhibits autoimmune arthritis by regulating key immune mediators of inflammation and bone damage. International Journal of Immunopathology and Pharmacology. 2015; 28: 521-531.

[88] Singh H, Kaur T, Manchanda S, Kaur G. Intermittent fasting combined with supplementation with Ayurvedic herbs reduces anxiety in middle aged female rats by anti-inflammatory path- 
ways. Biogerontology. 2017; 18: 601-614.

[89] Gupta PK, Chakraborty P, Kumar S, Singh PK, Rajan MGR, Sainis KB, et al. G1-4a, a polysaccharide from Tinospora cordifolia inhibits the survival of mycobacterium tuberculosis by modulating host immune responses in TLR4 dependent manner. PLoS ONE. 2016; 11: e0154725.

[90] Gupta PK, Rajan MGR, Kulkarni S. Activation of murine macrophages by G1-4a, a polysaccharide from Tinospora cordifolia, in TLR4/MyD88 dependent manner. International Immunopharmacology. 2017; 50: 168-177.

[91] Fu X, Wang Z, Li L, Dong S, Li Z, Jiang Z, et al. Novel chemical ligands to ebola virus and marburg virus nucleoproteins identified by combining affinity mass spectrometry and metabolomics approaches. Scientific Reports. 2016; 6: 29680.

[92] Murck H. Symptomatic protective action of glycyrrhizin (Licorice) in COVID-19 infection? Frontiers in Immunology. 2020; 11: 1239.

[93] van de Sand L, Bormann M, Alt M, Schipper L, Heilingloh CS, Todt D, et al. Glycyrrhizin effectively neutralizes SARS-CoV-2 in vitro by inhibiting the viral main protease. 2020. (in press)

[94] Armanini D, Fiore C, Bielenberg J, Sabbadin C, Bordin L. Coronavirus-19: possible therapeutic implications of spironolactone and dry extract of Glycyrrhiza glabra L. (Licorice). Frontiers in Pharmacology. 2020; 11: 558418.

[95] Bailly C, Vergoten G. Glycyrrhizin: an alternative drug for the treatment of COVID-19 infection and the associated respiratory syndrome? Pharmacology \& Therapeutics. 2020; 214: 107618.

[96] Srivastava V, Yadav A, Sarkar P. Molecular docking and ADMET study of bioactive compounds of Glycyrrhiza glabra against main protease of SARS-CoV2. Materials Today: Proceedings. 2020; 300.

[97] Sinha SK, Prasad SK, Islam MA, Gurav SS, Patil RB, AlFaris NA, et al. Identification of bioactive compounds from Glycyrrhiza glabra as possible inhibitor of SARS-CoV-2 spike glycoprotein and non-structural protein-15: a pharmacoinformatics study. Journal of Biomolecular Structure and Dynamics. 2020; $1-15$.

[98] Sun Y, Aryal P, Jiang M, Wu S, Park P, Song K. Correction to: transcriptional suppression of androgen receptor by $18 \beta$-glycyrrhetinic acid in LNCaP human prostate cancer cells. Archives of Pharmacal Research. 2020; 43: 875-875.

[99] Lee SA, Lee SH, Kim JY, Lee WS. Effects of glycyrrhizin on lipopolysaccharide-induced acute lung injury in a mouse model. Journal of Thoracic Disease. 2019; 11: 1287-1302.

[100] Kong D, Wang Z, Tian J, Liu T, Zhou H. Glycyrrhizin inactivates toll-like receptor (TLR) signaling pathway to reduce lipopolysaccharide-induced acute lung injury by inhibiting TLR2. Journal of Cellular Physiology. 2019; 234: 4597-4607.

[101] Fei L, Jifeng F, Tiantian W, Yi H, Linghui P. Glycyrrhizin ameliorate ischemia reperfusion lung injury through downregulate TLR2 signaling cascade in alveolar macrophages. Frontiers in Pharmacology. 2017; 8: 389.

[102] Zhao H, Zhao M, Wang Y, Li F, Zhang Z. Glycyrrhizic acid prevents sepsis-induced acute lung injury and mortality in rats. The Journal of Histochemistry and Cytochemistry. 2016; 64: 125-137.

[103] Alali FQ, El-Elimat T, Khalid L, Hudaib R, Al-Shehabi TS, Eid AH. Garlic for cardiovascular disease: prevention or treatment? Current Pharmaceutical Design. 2017; 23: 1028-1041.

[104] Sun YE, Wang W, Qin J. Anti-hyperlipidemia of garlic by reducing the level of total cholesterol and low-density lipoprotein. Medicine. 2018; 97: e0255-e0255.

[105] Pârvu M, Moţ CA, Pârvu AE, Mircea C, Stoeber L, RoşcaCasian $\mathrm{O}$, et al. Allium sativum extract chemical composition, antioxidant activity and antifungal effect against meyerozyma guilliermondii and rhodotorula mucilaginosa causing onychomycosis. Molecules. 2019; 24: 3958.

[106] Arellano Buendía AS, Tostado González M, Sánchez Reyes
O, García Arroyo FE, Argüello García R, Tapia E, et al. Immunomodulatory effects of the nutraceutical garlic derivative allicin in the progression of diabetic nephropathy. International Journal of Molecular Sciences. 2018; 19: 3107.

[107] Padiya R, Banerjee SK. Garlic as an anti-diabetic agent: recent progress and patent reviews. Recent Patents on Food, Nutrition \& Agriculture. 2013; 5: 105-127.

[108] Zhu Y, Anand R, Geng X, Ding Y. A mini review: garlic extract and vascular diseases. Neurological Research. 2018; 40: 421425.

[109] Reiter J, Levina N, van der Linden M, Gruhlke M, Martin C, Slusarenko AJ. Diallylthiosulfinate (Allicin), a volatile antimicrobial from Garlic (Allium sativum), kills human lung pathogenic bacteria, including MDR strains, as a vapor. Molecules. 2017; 22: 1711.

[110] Bhatwalkar SB, Gound SS, Mondal R, Srivastava RK, Anupam R. Anti-biofilm and antibacterial activity of Allium sativum against drug resistant Shiga-toxin producing escherichia coli (STEC) isolates from patient samples and food sources. Indian Journal of Medical Microbiology. 2019; 59: 171-179.

[111] Thuy BTP, My TTA, Hai NTT, Hieu LT, Hoa TT, Thi Phuong Loan $\mathrm{H}$, et al. Investigation into SARS-CoV-2 resistance of compounds in garlic essential oil. ACS Omega. 2020; 5: 8312-8320.

[112] Donma MM, Donma O. The effects of allium sativum on immunity within the scope of COVID-19 infection. Medical Hypotheses. 2020; 144: 109934.

[113] Khubber S, Hashemifesharaki R, Mohammadi M, Gharibzahedi SMT. Garlic (Allium sativum L.): a potential unique therapeutic food rich in organosulfur and flavonoid compounds to fight with COVID-19. Nutrition Journal. 2020; 19: 124.

[114] Pandey P, Khan F, Kumar A, Srivastava A, Jha NK. Screening of potent inhibitors against 2019 novel coronavirus (Covid19) from Alliumsativum and Allium cepa: an in silico approach. Biointerface Research in Applied Chemistry. 2020; 11: 79817993.

[115] Hsieh CC, Liu KF, Liu PC, Ho YT, Li WS, Peng WH, et al. Comparing the protection imparted by different fraction extracts of garlic (Allium sativum L.) against Der p-induced allergic airway inflammation in mice. International Journal of Molecular Sciences. 2019; 20: 4879.

[116] Khajevand-Khazaei M, Azimi S, Sedighnejad L, Salari S, Ghorbanpour A, Baluchnejadmojarad T, et al. S-allyl cysteine protects against lipopolysaccharide-induced acute kidney injury in the C57BL/6 mouse strain: involvement of oxidative stress and inflammation. International Immunopharmacology. 2019; 69: 19-26.

[117] Ansari M, Porouhan P, Mohammadianpanah M, Omidvari S, Mosalaei A, Ahmadloo N, et al. Efficacy of ginger in control of chemotherapy induced nausea and vomiting in breast cancer patients receiving doxorubicin-based chemotherapy. Asian Pacific Journal of Cancer Prevention. 2016; 17: 3877-3880.

[118] Maghbooli M, Golipour F, Moghimi Esfandabadi A, Yousefi $\mathrm{M}$. Comparison between the efficacy of ginger and sumatriptan in the ablative treatment of the common migraine. Phytotherapy Research. 2014; 28: 412-415.

[119] Arablou T, Aryaeian N, Valizadeh M, Sharifi F, Hosseini A, Djalali M. The effect of ginger consumption on glycemic status, lipid profile and some inflammatory markers in patients with type 2 diabetes mellitus. International Journal of Food Sciences and Nutrition. 2014; 65: 515-520

[120] Al Hroob AM, Abukhalil MH, Alghonmeen RD, Mahmoud AM. Ginger alleviates hyperglycemia-induced oxidative stress, inflammation and apoptosis and protects rats against diabetic nephropathy. Biomedicine \& Pharmacotherapy. 2018; 106: 381-389.

[121] Tanaka K, Arita M, Sakurai H, Ono N, Tezuka Y. Analysis of chemical properties of edible and medicinal ginger by metabolomics approach. BioMed Research International. 2015; 2015: 1-7. 
[122] Park M, Bae J, Lee DS. Antibacterial activity of [10]-gingerol and [12]-gingerol isolated from ginger rhizome against periodontal bacteria. Phytotherapy Research. 2008; 22: 1446-1449.

[123] Ezzat SM, Ezzat MI, Okba MM, Menze ET, Abdel-Naim $\mathrm{AB}$. The hidden mechanism beyond ginger (Zingiber officinale Rosc.) potent in vivo and in vitro anti-inflammatory activity. Journal of Ethnopharmacology. 2018; 214: 113-123.

[124] Mohd Sahardi NFN, Makpol S. Ginger (Zingiber officinale Roscoe) in the prevention of ageing and degenerative diseases: review of current evidence. Evidence-Based Complementary and Alternative Medicine. 2019; 2019: 1-13.

[125] Si W, Chen YP, Zhang J, Chen Z, Chung HY. Antioxidant activities of ginger extract and its constituents toward lipids. Food Chemistry. 2018; 239: 1117-1125.

[126] Hussein UK, Hassan NEY, Elhalwagy MEA, Zaki AR, Abubakr HO, Nagulapalli Venkata KC, et al. Ginger and propolis exert neuroprotective effects against monosodium glutamateinduced neurotoxicity in rats. Molecules. 2017; 22: 1928.

[127] Pashaei-Asl R, Pashaei-Asl F, Mostafa Gharabaghi P, Khodadadi K, Ebrahimi M, Ebrahimie E, et al. The inhibitory effect of ginger extract on ovarian cancer cell line; application of systems biology. Advanced Pharmaceutical Bulletin. 2017; 7: 241-249.

[128] de Lima RMT, dos Reis AC, de Menezes APM, Santos JVDO, Filho JWGDO, Ferreira JRDO, et al. Protective and therapeutic potential of ginger (Zingiber officinale) extract and [6]-gingerol in cancer: a comprehensive review. Phytotherapy Research. 2018; 32: 1885-1907.

[129] Yao J, Du Z, Li Z, Zhang S, Lin Y, Li H, et al. 6-Gingerol as an arginase inhibitor prevents urethane-induced lung carcinogenesis by reprogramming tumor supporting M2 macrophages to M1 phenotype. Food \& Function. 2018; 9: 4611-4620.

[130] Li X, Qin Y, Liu W, Zhou X, Li Y, Wang L. Efficacy of ginger in ameliorating acute and delayed chemotherapy-induced nausea and vomiting among patients with lung cancer receiving cisplatin-based regimens: a randomized controlled trial. Integrative Cancer Therapies. 2018; 17: 747-754.

[131] Dermani FK, Amini R, Saidijam M, Pourjafar M, Saki S, Najafi R. Zerumbone inhibits epithelial-mesenchymal transition and cancer stem cells properties by inhibiting the $\beta$-catenin pathway through miR-200c. Journal of Cellular Physiology. 2018; 233: 9538-9547.

[132] D Goswami, M Kumar, S Ghosh, A Das. Natural product compounds in alpinia officinarum and ginger are potent SARS-CoV2 papain-like protease inhibitors. ChemRxiv. 2020. (in press)

[133] Haridas M, Sasidhar V, Nath P, Abhithaj J, Sabu A, Rammanohar P. Compounds of Citrus medica and Zingiber officinale for COVID-19 inhibition: in silico evidence for cues from Ayurveda. Future Journal of Pharmaceutical Sciences. 2021; 7: 13.

[134] Çifci A, Tayman C, Yakut Hİ, Halil H, Çakır E, Çakır U, et al. Ginger (Zingiber officinale) prevents severe damage to the lungs due to hyperoxia and inflammation. Turkish Journal of Medical Sciences. 2018; 48: 892-900.

[135] Aggarwal BB, Kumar A, Bharti AC. Anticancer potential of curcumin: preclinical and clinical studies. Anticancer Research. 2003; 23: 363-398.

[136] Padilla-S L, Rodríguez A, Gonzales MM, Gallego-G JC, Castaño-O JC. Inhibitory effects of curcumin on dengue virus type 2-infected cells in vitro. Archives of Virology. 2014; 159: 573-579.

[137] Kutluay SB, Doroghazi J, Roemer ME, Triezenberg SJ. Curcumin inhibits herpes simplex virus immediate-early gene expression by a mechanism independent of p300/CBP histone acetyltransferase activity. Virology. 2008; 373: 239-247.

[138] Mazumder A, Raghavan K, Weinstein J, Kohn KW, Pommier Y. Inhibition of human immunodeficiency virus type-1 integrase by curcumin. Biochemical Pharmacology. 1995; 49: 1165-1170.
[139] Mounce BC, Cesaro T, Carrau L, Vallet T, Vignuzzi M. Curcumin inhibits Zika and chikungunya virus infection by inhibiting cell binding. Antiviral Research. 2017; 142: 148-157.

[140] Han S, Xu J, Guo X, Huang M. Curcumin ameliorates severe influenza pneumonia via attenuating lung injury and regulating macrophage cytokines production. Clinical and Experimental Pharmacology and Physiology. 2018; 45: 84-93.

[141] Zahedipour F, Hosseini SA, Sathyapalan T, Majeed M, Jamialahmadi T, Al-Rasadi K, et al. Potential effects of curcumin in the treatment of COVID-19 infection. Phytotherapy Research. 2020; 34: 2911-2920.

[142] Maurya VK, Kumar S, Prasad AK, Bhatt MLB, Saxena SK. Structure-based drug designing for potential antiviral activity of selected natural products from Ayurveda against SARS-CoV-2 spike glycoprotein and its cellular receptor. VirusDisease. 2020; 31: 179-193.

[143] S Khaerunnisa, H Kurniawan, R Awaluddin, S Suhartati. Potential inhibitor of COVID-19 main protease (M pro) from several medicinal plant compounds by molecular docking study. Preprints. 2020; $1-14$.

[144] AK Srivastava, D Singh. Destabilizing the structural integrity of SARS-CoV2 receptor proteins by curcumin along with hydroxychloroquine: an Insilco approach for a combination therapy. ChemRxiv. 2020. (in press)

[145] Hasanzadeh S, Read MI, Bland AR, Majeed M, Jamialahmadi T, Sahebkar A. Curcumin: an inflammasome silencer. Pharmacological Research. 2020; 159: 104921.

[146] Zhang M, Xie Y, Yan R, Shan H, Tang J, Cai Y, et al. Curcumin ameliorates alveolar epithelial injury in a rat model of chronic obstructive pulmonary disease. Life Sciences. 2016; 164: 1-8.

[147] Lelli D, Sahebkar A, Johnston TP, Pedone C. Curcumin use in pulmonary diseases: state of the art and future perspectives. Pharmacological Research. 2017; 115: 133-148.

[148] Feng T, Wei Y, Lee RJ, Zhao L. Liposomal curcumin and its application in cancer. International Journal of Nanomedicine. 2017; 12: 6027-6044.

[149] Dos Santos PDF, Francisco CRL, Coqueiro A, Leimann FV, Pinela J, Calhelha RC, et al. The nanoencapsulation of curcuminoids extracted from Curcuma longa L. and an evaluation of their cytotoxic, enzymatic, antioxidant and anti-inflammatory activities. Food \& Function. 2019; 10: 573-582.

[150] Hu Y, Li M, Zhang M, Jin Y. Inhalation treatment of idiopathic pulmonary fibrosis with curcumin large porous microparticles. International Journal of Pharmaceutics. 2018; 551: 212-222.

[151] Lee W, Loo C, Young PM, Rohanizadeh R, Traini D. Curcumin nanoparticles attenuate production of pro-inflammatory markers in lipopolysaccharide-induced macrophages. Pharmaceutical Research. 2016; 33: 315-327.

[152] Dorri M, Hashemitabar S, Hosseinzadeh H. Cinnamon (Cinnamomum zeylanicum) as an antidote or a protective agent against natural or chemical toxicities: a review. Drug and Chemical Toxicology. 2018; 41: 338-351.

[153] Ibrahim IM, Abdelmalek DH, Elfiky AA. GRP78: a cell's response to stress. Life Sciences. 2019; 226: 156-163.

[154] Ibrahim I, Abdelmalek D, Elshahat M, Elfiky A. COVID-19 Spike-host cell receptor GRP78 binding site prediction. Research Square. 2020; 1-21. (in press)

[155] Neto JGO, Boechat SK, Romão JS, Pazos-Moura CC, Oliveira KJ. Treatment with cinnamaldehyde reduces the visceral adiposity and regulates lipid metabolism, autophagy and endoplasmic reticulum stress in the liver of a rat model of early obesity. Journal of Nutritional Biochemistry. 2020; 77: 108321.

[156] Elfiky AA. Natural products may interfere with SARS-CoV-2 attachment to the host cell. Journal of Biomolecular Structure and Dynamics. 2020; 1-10.

[157] Prasanth DSNBK, Murahari M, Chandramohan V, Panda SP, Atmakuri LR, Guntupalli C. In silico identification of potential inhibitors from Cinnamon against main protease and spike glycoprotein of SARS CoV-2. Journal of Biomolecular Structure 
and Dynamics. 2020; 1-15.

[158] Gautam S, Gautam A, Chhetri S, Bhattarai U. Immunity against COVID-19: Potential role of Ayush Kwath. Journal of Ayurveda and Integrative Medicine. 2020; 579

[159] Ho S, Chang K, Chang P. Inhibition of neuroinflammation by cinnamon and its main components. Food Chemistry. 2013; 138: 2275-2282.

[160] Schink A, Naumoska K, Kitanovski Z, Kampf CJ, FröhlichNowoisky J, Thines E, et al. Anti-inflammatory effects of cinnamon extract and identification of active compounds influencing the TLR2 and TLR4 signaling pathways. Food \& Function. 2018; 9: 5950-5964.

[161] Stohs SJ, Hartman MJ. Review of the safety and efficacy of moringa oleifera. Phytotherapy Research: PTR. 2015; 29: 796804.

[162] Vergara-Jimenez M, Almatrafi MM, Fernandez ML. Bioactive components in moringa oleifera leaves protect against chronic disease. Antioxidants. 2019; 6: 91.

[163] Omodanisi EI, Aboua YG, Oguntibeju OO. Assessment of the anti-hyperglycaemic, anti-inflammatory and antioxidant activities of the methanol extract of moringa oleifera in diabetesinduced nephrotoxic male wistar rats. Molecules. 2017; 22: 439.

[164] Sujitha V, Murugan K, Paulpandi M, Panneerselvam C, Suresh $\mathrm{U}$, Roni M, et al. Green-synthesized silver nanoparticles as a novel control tool against dengue virus (DEN-2) and its primary vector Aedes aegypti. Parasitology Research. 2015; 114: 33153325.

[165] Tiloke C, Phulukdaree A, Anand K, Gengan RM, Chuturgoon AA. Moringa oleifera gold nanoparticles modulate oncogenes, tumor suppressor genes, and Caspase- 9 splice variants in a549 cells. Journal of Cellular Biochemistry. 2016; 117: 2302-2314.

[166] Matic I, Guidi A, Kenzo M, Mattei M, Galgani A. Investigation of medicinal plants traditionally used as dietary supplements: a review on Moringa oleifera. Journal of Public Health in Africa. 2018; 9: 841.

[167] Shaji D. Computational identification of drug lead compounds for COVID-19 from Moringa Oleifera. ChemRxiv. 2020. (in press)

[168] Nair AD, JT J. Computational screening of phytocompounds from Moringa oleifera leaf as potential inhibitors of SARS-CoV2 Mpro. 2020. (in press)

[169] Hamza M, Ali A, Khan S, Ahmed S, Attique Z, et al. nCOV-19 peptides mass fingerprinting identification, binding, and blocking of inhibitors flavonoids and anthraquinone of Moringa oleifera and hydroxychloroquine. Journal of Biomolecular Structure and Dynamics. 2020; 1-11.

[170] Tan WS, Arulselvan P, Karthivashan G, Fakurazi S. Moringa oleifera Flower Extract Suppresses the Activation of Inflammatory Mediators in Lipopolysaccharide-Stimulated RAW 264.7 Macrophages via NF-kB Pathway. Mediators of Inflammation. 2015; 2015: 720171.

[171] Jaja-Chimedza A, Graf BL, Simmler C, Kim Y, Kuhn P, Pauli GF, et al. Biochemical characterization and anti-inflammatory properties of an isothiocyanate-enriched moringa (Moringa oleifera) seed extract. PLoS ONE. 2017; 12: e0182658.

[172] Cui C, Chen S, Wang X, Yuan G, Jiang F, Chen X, et al. Characterization of Moringa oleifera roots polysaccharide MRP-1 with anti-inflammatory effect. International Journal of Biological Macromolecules. 2019; 132: 844-851.

[173] Gupta SC, Prasad S, Tyagi AK, Kunnumakkara AB, Aggarwal BB. Neem (Azadirachta indica): an indian traditional panacea with modern molecular basis. Phytomedicine. 2017; 34: 14-20.

[174] Habluetzel A, Pinto B, Tapanelli S, Nkouangang J, Saviozzi M, Chianese G, et al. Effects of Azadirachta indica seed kernel extracts on early erythrocytic schizogony of Plasmodium berghei and pro-inflammatory response in inbred mice. Malaria Journal. 2019; 18: 35.

[175] Morris J, Gonzales CB, De La Chapa JJ, Cabang AB, Fountzi- las C, Patel M, et al. The highly pure neem leaf extract, SCNE, inhibits tumorigenesis in oral squamous cell carcinoma via disruption of pro-tumor inflammatory cytokines and cell signaling. Frontiers in Oncology. 2019; 9: 890.

[176] Borkotoky S, Banerjee M. A computational prediction of SARS-CoV-2 structural protein inhibitors from Azadirachta indica (Neem). Journal of Biomolecular Structure and Dynamics. 2020; 1-11.

[177] Subramanian S. Nearly 20+ compounds in Neem leaves extract exhibit high binding affinity with some of them as high as -14.3 kcal/mol against COVID-19 Main Protease (Mpro): A Molecular Docking Study. 2020.

[178] Baildya N, Khan AA, Ghosh NN, Dutta T, Chattopadhyay AP. Screening of potential drug from Azadirachta Indica (Neem) extracts for SARS-CoV-2: an insight from molecular docking and MD-simulation studies. Journal of Molecular Structure. 2021; 1227: 129390.

[179] Dwivedi VD, Bharadwaj S, Afroz S, Khan N, Ansari MA, Yadava U, et al. Anti-dengue infectivity evaluation of bioflavonoid from Azadirachta indica by dengue virus serine protease inhibition. Journal of Biomolecular Structure and Dynamics. 2020; 39: 1417-1430.

[180] Lee J, Ryu HW, Park S, Park HA, Kwon O, Yuk HJ, et al. Protective effects of neem (Azadirachta indica a. Juss.) leaf extract against cigarette smoke- and lipopolysaccharide-induced pulmonary inflammation. International Journal of Molecular Medicine. 2017; 40: 1932-1940.

[181] Pooladanda V, Thatikonda S, Bale S, Pattnaik B, Sigalapalli DK, Bathini NB, et al. Nimbolide protects against endotoxininduced acute respiratory distress syndrome by inhibiting TNF$\alpha$ mediated NF-kB and HDAC-3 nuclear translocation. Cell Death \& Disease. 2019; 10: 81.

[182] Seo JY, Lee C, Hwang SW, Chun J, Im JP, Kim JS. Nimbolide Inhibits Nuclear Factor-KB Pathway in Intestinal Epithelial Cells and Macrophages and Alleviates Experimental Colitis in Mice. Phytotherapy Research: PTR. 2016; 30: 1605-1614.

[183] Cohen MM. Tulsi - Ocimum sanctum: a herb for all reasons. Journal of Ayurveda and Integrative Medicine. 2014; 5: 251259.

[184] Ghoke SS, Sood R, Kumar N, Pateriya AK, Bhatia S, Mishra A, et al. Evaluation of antiviral activity of Ocimum sanctum and Acacia arabica leaves extracts against H9N2 virus using embryonated chicken egg model. BMC Complementary and Alternative Medicine. 2018; 18: 174.

[185] Saikia S, Bordoloi M, Sarmah R, Kolita B. Antiviral compound screening, peptide designing, and protein network construction of influenza a virus (strain a/Puerto Rico/8/1934 H1N1). Drug Development Research. 2019; 80: 106-124.

[186] Tang LIC, Ling APK, Koh RY, Chye SM, Voon KGL. Screening of anti-dengue activity in methanolic extracts of medicinal plants. BMC Complementary and Alternative Medicine. 2012; 12: 3.

[187] Sonar VP, Corona A, Distinto S, Maccioni E, Meleddu R, Fois $B$, et al. Natural product-inspired esters and amides of ferulic and caffeic acid as dual inhibitors of HIV-1 reverse transcriptase. European Journal of Medicinal Chemistry. 2017; 130: 248-260.

[188] Mohapatra PK, Chopdar KS, Dash GC, Raval MK. In silico screening of phytochemicals of ocimum sanctum against main protease of SARS-CoV-2. ChemRxiv. 2020. (in press)

[189] Varshney KK, Varshney M, Nath B. Molecular modeling of isolated phytochemicals from ocimum sanctum towards exploring potential inhibitors of SARS coronavirus main protease and papain-like protease to treat COVID-19. 2020. Available at SSRN: https://ssrn.com/abstract=3554371 (Accessed: January 2021).

[190] Choudhury SS, Bashyam L, Manthapuram N, Bitla P, Kollipara $\mathrm{P}$, Tetali SD. Ocimum sanctum leaf extracts attenuate human monocytic (THP-1) cell activation. Journal of Ethnopharmacology. 2014; 154: 148-155. 
[191] Venuprasad MP, Kandikattu HK, Razack S, Amruta N, Khanum F. Chemical composition of Ocimum sanctum by LCESI-MS/MS analysis and its protective effects against smoke induced lung and neuronal tissue damage in rats. Biomedicine \& Pharmacotherapy. 2017; 91: 1-12.

[192] Meghwani H, Prabhakar P, Mohammed SA, Dua P, Seth S, Hote MP, et al. Beneficial effect of Ocimum sanctum (Linn) against monocrotaline-induced pulmonary hypertension in rats. Medicines. 2019; 5: 34.

[193] Prasanth MI, Sivamaruthi BS, Chaiyasut C, Tencomnao T. A review of the role of green tea (Camellia sinensis) in antiphotoaging, stress resistance, neuroprotection, and autophagy. Nutrients. 2019; 11: 474.

[194] Pervin M, Unno K, Ohishi T, Tanabe H, Miyoshi N, Nakamura Y. Beneficial effects of green tea catechins on neurodegenerative diseases. Molecules. 2018; 23: 1297.

[195] Malkoç M, Patan H, Yaman SÖ, Türedi S, Kerimoğlu G, Kural $\mathrm{BV}$, et al. L-theanine alleviates liver and kidney dysfunction in septic rats induced by cecal ligation and puncture. Life Sciences. 2020; 249: 117502.

[196] Song J. Anti-infective potential of catechins and their derivatives against viral hepatitis. Clinical and Experimental Vaccine Research. 2018; 7: 37.

[197] Sharma S, Deep S. In-silico drug repurposing for targeting SARS-CoV-2 Mpro. ChemRxiv. 2020. (in press)

[198] Kanbarkar N, Mishra S. Matrix metalloproteinase inhibitors identified from Camellia sinensis for COVID-19 prophylaxis: an in silico approach. Advances in Integrative Medicine. 2020.

[199] Mhatre S, Srivastava T, Naik S, Patravale V. Antiviral activity of green tea and black tea polyphenols in prophylaxis and treatment of COVID-19: a review. Phytomedicine. 2020; 83: 153286.

[200] Upadhyay S, Tripathi PK, Singh M, Raghavendhar S, Bhardwaj M, Patel AK. Evaluation of medicinal herbs as a potential therapeutic option against SARS $\mathrm{CoV} 2$ targeting its main protease. Phytotherapy Research. 2020; 34: 3411-3419.

[201] Chowdhury P, Barooah AK. Tea bioactive modulate innate immunity: in perception to COVID-19 pandemic. Frontiers in Immunology. 2020; 11: 590716.

[202] Ohishi T, Goto S, Monira P, Isemura M, Nakamura Y. Antiinflammatory action of green tea. Anti-Inflammatory \& AntiAllergy Agents in Medicinal Chemistry. 2016; 15: 74-90.

[203] Tasneem S, Liu B, Li B, Choudhary MI, Wang W. Molecular pharmacology of inflammation: medicinal plants as antiinflammatory agents. Pharmacological Research. 2019; 139: 126-140.

[204] Wang D, Gao Q, Zhao G, Kan Z, Wang X, Wang H, et al. Protective effect and mechanism of theanine on lipopolysaccharideinduced inflammation and acute liver injury in mice. Journal of Agricultural and Food Chemistry. 2018; 66: 7674-7683.

[205] Liu Y, Wang X, Chen Q, Luo L, Ma M, Xiao B, et al. Camellia sinensis and Litsea coreana ameliorate intestinal inflammation and modulate gut microbiota in dextran sulfate sodium-induced colitis mice. Molecular Nutrition \& Food Research. 2020; 64: 1900943.

[206] St. John TM. Chronic hepatitis. Integrative Medicine. 2007; 47: 237-256.

[207] Zhang P, Liu X, Liu H, Wang W, Liu X, Li X, et al. Astragalus polysaccharides inhibit avian infectious bronchitis virus infection by regulating viral replication. Microbial Pathogenesis. 2018; 114: 124-128.

[208] Liu T, Zhang M, Niu H, Liu J, Ruilian M, Wang Y, et al. Astragalus polysaccharide from Astragalus Melittin ameliorates inflammation via suppressing the activation of TLR-4/NF-kB p65 signal pathway and protects mice from CVB3-induced virus myocarditis. International Journal of Biological Macromolecules. 2019; 126: 179-186.

[209] Xue H, Gan F, Qian G, Hu J, Hao S, Xu J, et al. Astragalus polysaccharides attenuate PCV2 infection by inhibiting endo- plasmic reticulum stress in vivo and in vitro. Scientific Reports. 2017; 7: 40440.

[210] Zhou L, Liu Z, Wang Z, Yu S, Long T, Zhou X, et al. Astragalus polysaccharides exerts immunomodulatory effects via TLR4-mediated MyD88-dependent signaling pathway in vitro and in vivo. Scientific Reports. 2017; 7: 44822.

[211] Bamodu OA, Kuo KT, Wang C-H, Huang W-C, Wu ATH, Tsai $\mathrm{J}-\mathrm{T}$, et al. Astragalus polysaccharides (PG2) enhances the M1 polarization of macrophages, functional maturation of dendritic cells, and t cell-mediated anticancer immune responses in patients with lung cancer. Nutrients. 2019; 11: 2264.

[212] Dong N, Li X, Xue C, Wang C, Xu X, Bi C, et al. Astragalus polysaccharides attenuated inflammation and balanced the gut microflora in mice challenged with Salmonella typhimurium. International Immunopharmacology. 2018; 74: 105681.

[213] Li J, Xu L, Sang R, Yu Y, Ge B, Zhang X. Immunomodulatory and anti-inflammatory effects of total flavonoids of Astragalus by regulating NF-KB and MAPK signalling pathways in RAW 264.7 macrophages. Die Pharmazie. 2019; 73: 589-593.

[214] Li H, Peng Y, Wang X, Sun X, Yang F, Sun Y, et al. Astragaloside inhibits IL- $1 \beta$-induced inflammatory response in human osteoarthritis chondrocytes and ameliorates the progression of osteoarthritis in mice. Immunopharmacology and Immunotoxicology. 2019; 41: 497-503.

[215] Shahzad M, Shabbir A, Wojcikowski K, Wohlmuth H, Gobe GC. The antioxidant effects of radix astragali (Astragalus membranaceus and related species) in protecting tissues from injury and disease. Current Drug Targets. 2016; 17: 1331-1340.

[216] Chu X, Liu X, Qiu J, Zeng X, Bao H, Shu J. Effects of Astragalus and Codonopsis pilosula polysaccharides on alveolar macrophage phagocytosis and inflammation in chronic obstructive pulmonary disease mice exposed to PM2.5. Environmental Toxicology and Pharmacology. 2016; 48: 76-84.

[217] Qin L, Tan H, Wang Y, Xu C, Feng J, Li M, et al. Astragalus membranaceus and salvia miltiorrhiza ameliorate lipopolysaccharide-induced acute lung injury in rats by regulating the toll-like receptor 4/nuclear factor-kappa B signaling pathway. Evidence-Based Complementary and Alternative Medicine. 2018; 2018: 3017571.

[218] Wu T, Yeh K, Wang C, Wang H, Li T, Chan Y, et al. The combination of astragalus membranaceus and angelica sinensis inhibits lung cancer and cachexia through its immunomodulatory function. Journal of Oncology. 2019; 2019: 1-15.

[219] Yan X, Lu Q, Zeng L, Li X, Liu Y, Du X, et al. Synergistic protection of astragalus polysaccharides and matrine against ulcerative colitis and associated lung injury in rats. World Journal of Gastroenterology. 2020; 26: 55-69.

[220] Bezerra DP, Pessoa C, de Moraes MO, Saker-Neto N, Silveira ER, Costa-Lotufo LV. Overview of the therapeutic potential of piplartine (piperlongumine). European Journal of Pharmaceutical Sciences. 2013; 48: 453-463.

[221] Gagat M, Hałas-Wiśniewska M, Zielińska W, Izdebska M, Grzanka D, Grzanka A. The effect of piperlongumine on endothelial and lung adenocarcinoma cells with regulated expression of profilin-1. OncoTargets and Therapy. 2018; 11: 82758292.

[222] Avila-Carrasco L, Majano P, Sánchez-Toméro JA, Selgas R, López-Cabrera M, Aguilera A, et al. Natural plants compounds as modulators of epithelial-to-mesenchymal transition. Frontiers in Pharmacology. 2019; 10: 715.

[223] Joshi T, Joshi T, Sharma P, Mathpal S, Pundir H, Bhatt V, et al. In silico screening of natural compounds against COVID-19 by targeting Mpro and ACE2 using molecular docking. European Review for Medical and Pharmacological Sciences. 2020; 24: 4529-4536.

[224] Lu C, Zhang B, Xu T, Zhang W, Bai B, Xiao Z, et al. Piperlongumine reduces ovalbumin-induced asthma and airway inflammation by regulating nuclear factor- $\mathrm{KB}$ activation. International Journal of Molecular Medicine. 2019; 44: 1855-1865. 
[225] Amaral-Machado L, Oliveira WN, Moreira-Oliveira SS, Pereira DT, Alencar ÉN, Tsapis N, et al. Use of natural products in asthma treatment. Evidence-Based Complementary and Alternative Medicine. 2020; 2020: 1-35.

[226] Kim N, Do J, Bae J, Jin HK, Kim J, Inn K, et al. Piperlongumine inhibits neuroinflammation via regulating NF-kB signaling pathways in lipopolysaccharide-stimulated BV2 microglia cells. Journal of Pharmacological Sciences. 2018; 137: 195-201.

[227] Viola A, Munari F, Sánchez-Rodríguez R, Scolaro T, Castegna A. The metabolic signature of macrophage responses. Frontiers in Immunology. 2019; 10: 1462.

[228] Zhou L, Li M, Yu X, Gao F, Li W. Repression of hexokinases II-mediated glycolysis contributes to piperlongumine-induced tumor suppression in non-small cell lung cancer cells. International Journal of Biological Sciences. 2019; 15: 826-837.

[229] Sant'Ana M, Souza HR, Possebon L, Cornélio ML, RiffoVasquez Y, Girol AP, et al. Effect of piperlongumine during exposure to cigarette smoke reduces inflammation and lung injury. Pulmonary Pharmacology \& Therapeutics. 2020; 61: 101896.

[230] Bullova P, Cougnoux A, Abunimer L, Kopacek J, Pastorekova S, Pacak K. Hypoxia potentiates the cytotoxic effect of piperlongumine in pheochromocytoma models. Oncotarget. 2016; 7: 40531-40545.

[231] Govindarajan R, Singh DP, Rawat AKS. High-performance liquid chromatographic method for the quantification of phenolics in 'Chyavanprash' a potent Ayurvedic drug. Journal of Pharmaceutical and Biomedical Analysis. 2007; 43: 527-532.

[232] Poltanov EA, Shikov AN, Dorman HJD, Pozharitskaya ON, Makarov VG, Tikhonov VP, et al. Chemical and antioxidant evaluation of Indian gooseberry ( emblica officinalis gaertn., syn. phyllanthus emblica L.) supplements. Phytotherapy Research. 2009; 23: 1309-1315.

[233] Wu C, Liu Y, Yang Y, Zhang P, Zhong W, Wang Y, et al. Analysis of therapeutic targets for SARS-CoV-2 and discovery of potential drugs by computational methods. Acta Pharmaceutica Sinica B. 2020; 10: 766-788.

[234] Tahir Ul Qamar M, Alqahtani SM, Alamri MA, Chen LL. Structural basis of SARS-CoV-2 3CLpro and anti-COVID-19 drug discovery from medicinal plants. Journal of Pharmaceutical Analysis. 2020; 10: 313-319.

[235] Wang C, Yuan J, Wang C, Yang N, Chen J, Liu D, et al. Antiinflammatory effects of phyllanthus emblica $\mathrm{L}$ on benzopyreneinduced precancerous lung lesion by regulating the IL- $1 \beta / \mathrm{miR}$ 101/Lin28B signaling pathway. Integrative Cancer Therapies. 2017; 16: 505-515.

[236] Sripanidkulchai B, Junlatat J. Bioactivities of alcohol based extracts of Phyllanthus emblica branches: antioxidation, antimelanogenesis and anti-inflammation. Journal of Natural Medicines. 2014; 68: 615-622.

[237] Yang Y. Use of herbal drugs to treat COVID-19 should be with caution. The Lancet. 2020; 395: 1689-1690.

[238] Roshdy WH, Rashed HA, Kandeil A, Mostafa A, Moatasim Y, Kutkat O, et al. EGYVIR: an immunomodulatory herbal extract with potent antiviral activity against SARS-CoV-2. PLoS ONE. 2020; 15: e0241739.

Abbreviations: ACE2, angiotensin converting enzyme 2; ARDS, acute respiratory distress syndrome; BALF, bronchoalveolar lavage fluid; CD, cluster of differentiation; COX, cyclooxygenase; CSS, cytokine storm syndrome; ER, endoplasmic reticulum; IFN, interferon; IL, interleukin; iNOS, induced nitric oxide synthase; MCP-1, monocyte chemoattractant protein-1; MMP, matrix-metallo protease; NF- $\kappa \mathrm{B}$, Nuclear factor kappa B; TNF, tumor necrosis factor; TUNEL, Terminal deoxynucleotidyl transferase dUTP nick end labelling.

Keywords: COVID-19; Cytokine Storm Syndrome; CSS; Immune system; Phytotherapeutics; Review

Send correspondence to: Rupesh K. Srivastava, Department of Biotechnology, All India Institute of Medical Sciences (AIIMS), 110029 New Delhi, India, E-mail: rupesh_srivastava13@yahoo.co.in; rupeshk@aiims.edu 